\title{
Cloning and characterization of the segment polarity gene cubitus interruptus Dominant of Drosophila
}

\author{
Teresa V. Orenic, Diane C. Slusarski, Kristen L. Kroll, and Robert A. Holmgren \\ Department of Biochemistry, Molecular Biology, and Cell Biology, Northwestern University, Evanston, Illinois 60208 USA
}

\begin{abstract}
The segment polarity mutation, cubitus interruptus Dominant $\left(\mathrm{ci}^{\mathrm{D}}\right)$, of Drosophila melanogaster causes defects in the posterior half of every embryonic segment. We cloned sequences from the $\mathrm{ci}^{\mathrm{D}}$ region on the proximal fourth chromosome by "tagging" the gene with the transposable element P. Genetic and molecular evidence indicates that the P-element insertions, which all occurred within the same restriction fragment, are in 5'regulatory regions of the $c i^{D}$ gene within $3 \mathrm{~kb}$ of the first exon of its transcript. The putative $c i^{D}$ transcript was identified on the basis of its absence in homozygous $\mathrm{ci}^{D}$ embryos. Its spatial pattern of expression during development is unusual in that, unlike most other segmentation genes, it exhibits uniform expression throughout cellular blastoderm and gastrulation and does not resolve into a periodic pattern until the end of the fast phase of germ-band elongation when it is present in 15 broad segmentally repeating stripes along the anterior-posterior axis of the embryo. Registration of the $c i^{D}$ stripes of expression relative to the stripes of other segment polarity genes shows that $c i^{D}$ is expressed in the anterior three-quarters of every segment. This registration does not correlate with the pattern defects observed in $\mathrm{ci}^{\mathrm{D}}$ mutants. Sequence analysis indicates that the protein encoded by the $\mathrm{ci}^{D}$ transcript contains a domain of five tandem amino acid repeats that have sequence similarity to the zinc-finger repeats of the Xenopus transcription factor TFIIIA and that share the highest degree of identity with the human zinc-finger protein GLI, which has been found to be amplified in several human glioblastomas.
\end{abstract}

[Key Words: $\mathrm{ci}^{\mathrm{D}}$; Drosophila development; segment polarity genes; zinc-finger proteins]

Received January 17, 1990; revised version accepted March 26, 1990.

Drosophila embryos are divided into a series of repeating units called segments, which are the basic elements in the modular organization of the fly. To understand the biogenesis of segments, Nüsslein-Volhard and Wieschaus (1980) (Jurgens et al. 1984; Nüsslein-Volhard et al. 1984; Wieschaus et al. 1984/ did a systematic mutagenesis of the Drosophila genome and found three classes of genes, called gap, pair-rule, and segment polarity genes, that are required for proper segmentation. Most of the gap and pair-rule genes, and some of the segment polarity genes, have been cloned, and their expression patterns in developing embryos have been analyzed. Study of the interactions among the segmentation genes has shown that they function hierarchically with the gap genes regulating expression of the pair-rule genes, the pair-rule genes regulating expression of the segment polarity genes, and certain members of each class regulating expression of other members within their own class. The gap genes function in the initial division of the embryo into several domains, which results in expression of the pair-rule genes in position-specific patterns. The pair-rule genes divide the embryo into its segmental repeats. The segment polarity genes then function to establish pattern within the segments. Thus, it appears that the sequential function of the segmentation genes results in the division of the embryo into its segmental repeats with specific patterns in every segment (for review, see Akam 1987; Scott and Carroll 1987; Ingham 1988).

The phenotypes of embryos mutant for segment polarity genes suggest that these genes function in the generation of pattern within segments (Nüsslein-Volhard and Wieschaus 1980), and it was with the goal of understanding this process that we began our studies on the segment polarity gene, cubitus interruptus Dominant $\left(c i^{D}\right)$. The segment polarity mutations can be grouped according to the types of cuticle defects they cause. The first group includes mutations that eliminate the clear cuticle from the posterior half of every segment and replace it with a mirror image duplication of the anterior half of the segment. This class includes the armadillo $(\mathrm{arm}), \mathrm{ci}^{D}$, fused $(\mathrm{fu})$, and gooseberry $(\mathrm{gs} b)$ mutations (Nüsslein-Volhard and Wieschaus 1980; Nüsslein-Volhard et al. 1984; Wieschaus et al. 1984). The second class is composed of mutations that cause more extensive pattern defects with deletions of structures from the posterior of every segment as well as from the anterior margin of the adjacent segment. These embryos have 
disorganized denticle belts and are much smaller than wild type, indicating that cell death occurs in these mutants. Members of this class are hedgehog (hh), wingless $(w g)$, Cell (Ce), and dishevelled (dsh) (Nüsslein-Volhard and Wieschaus 1980; Jurgens et al. 1984; Wieschaus et al. 1984; Orenic et al. 1987; Perrimon and Mahowald 1987). Mutations of the third class cause deletions of the denticle belts from the anterior of every segment and their replacement with clear cuticle from the posterior of the segment. This class includes naked (nkd) and zeste-white $3(z-w 3)$ (Jurgens et al. 1984; Perrimon et al. 1989). The fourth class is made up of mutations that delete the middle of the segment and replace it with pattern elements from the anterior and posterior margins. In this class are patched (ptc) and costal-2 (cos-2) (Nüsslein-Volhard and Wieschaus 1980; Nüsslein-Volhard et al. 1984; Grau and Simpson 1987). In the fifth class is the engrailed (en) mutation, which causes breakdown of the posterior compartment, resulting in loss of the segment boundary, fusions between adjacent segments, and extensive pattern alterations (Lawrence and Morata 1976; Nüsslein-Volhard and Wieschaus 1980; Kornberg 1981a,b; Lawrence and Struhl 1982; Poole and Kornberg 1988).

Detailed studies of a number of the segment polarity genes have begun with the goal of understanding their respective roles in pattern formation. Six of the segment polarity genes have been cloned and characterized; these are en, gsb, wg, fu, arm, and ptc (Fjose et al. 1985; Kornberg et al. 1985; Kuner et al. 1985; Poole et al. 1985; Bopp et al. 1986; Baker 1987; Baumgartner et al. 1987; Cote et al. 1987; Mariol et al. 1987; Rijsewijk 1987; Hooper and Scott 1989; Nakano et al. 1989; Riggleman et al. 1989/. Of these, only the gsb expression pattern correlates well with the defects caused by the mutation (Bopp et al. 1986; Baumgartner et al. 1987; Cote et al. 1987). In both en and $w g$, mutants areas outside the regions of expression are altered (Fjose et al. 1985; Kornberg et al. 1985; Baker 1987). arm transcripts are uniformly distributed throughout embryogenesis, whereas the arm mutation affects primarily the posterior half of every segment (Riggleman et al. 1989). The pattern of ptc expression is quite dynamic during early embryogenesis, but it never perfectly correlates with the region affected in the mutant (Hooper and Scott 1989; Nakano et al. 1989).

The segment polarity genes have diverse functions and encode a heterogeneous array of proteins. The en gene functions to define the posterior compartment and establish the segmental repeat unit (Lawrence and Morata 1976; Kornberg 1981a,b; Lawrence and Struhl 1982; Poole and Kornberg 1988|. The gsb gene appears to be functioning to specify the fate of cells in the posterior half of the segment (A. Ungar and R. Holmgren, unpubl.). Both en and $g s b$ encode homeo box-containing proteins that probably function to regulate gene expression (DesPlan et al. 1985; Fiose et al. 1985; Poole et al. 1985; Bopp et al. 1986; Baumgartner et al. 1987). The wg gene has sequence similarity to the int-1 proto-oncogene of mouse, which encodes a secreted protein (Rijsewijk et al. 1987). It has been suggested that the wg gene functions in cell-cell communication because its protein product contains a signal sequence; its mutant phenotype is nonautonomous, and the $w g$ protein has been found in small vesicles and multivesicular bodies inside $w g$ expressing cells, in the intercellular space outside $w g$ expressing cells, and occasionally in cells adjacent to wg expressing cells (Rijsewijk et al. 1987; Baker 1988; van den Heuvel et al. 1989/. arm is maternally expressed, and the transcript is uniformly distributed in the embryo. The sequence of arm suggests that it is an intracellular protein, but its function is not yet known (Riggleman et al. 1989). The ptc gene encodes a putative transmembrane protein and is postulated to function in signal transduction (Hooper and Scott 1989; Nakano et al. 1989). Preliminary evidence indicates that regulatory interactions among the segment polarity genes and cell-cell communication are crucial elements in the process of pattern generation (DiNardo et al. 1988, Martinez-Arias et al. 1988).

The $c i^{D}$ mutation causes recessive pattern defects in developing embryos; structures in the posterior half of each segment are eliminated and replaced with a mirror image duplication of anterior structures on both the dorsal and ventral surfaces. $c i^{D}$ maps to the proximal fourth chromosome near another segment polarity mutation called Cell (Ce) (Nüsslein-Volhard 1980; Orenic et al. 1987). A genetic analysis of the region suggests that either the two loci are tightly linked or that $\mathrm{Ci}^{D}$ and $\mathrm{Ce}$ represent complementing alleles of the same gene (Hochman 1971, 1973, 1976; Orenic et al. 1987).

Here, we present evidence that we have cloned sequences from the $\mathrm{Ci}^{D}-\mathrm{Ce}$ region. Eaton and Kormberg (1990) have independently isolated sequences from the $\mathrm{Ci}^{D}-\mathrm{Ce}$ region by enhancer trapping, and our overlapping results are essentially in agreement. We have identified the $\mathrm{ci}^{D}$ transcript, studied its temporal and spatial pattern of expression, and have determined the nucleotide sequence of the protein-coding region. Like arm, en, ptc, and $w g$, its expression pattern never perfectly correlates with the regions deleted in the mutant. Sequence analysis shows that part of the transcript encodes a domain that has five tandem repeats similar to the zinc-finger repeats of the Xenopus transcription factor TFIIIA (Brown et al. 1985; Miller et al. 1985). Thus, $c i^{D}$ encodes a protein that is distinct from the proteins encoded by other members of the segment polarity class adding to the heterogeneity of this class of segmentation genes.

\section{Results}

Figure 1 provides a comparison of the segmentally repeating pattern of the ventral cuticle of a wild-type embryo (Fig. 1A) with the patterns caused by the recessive $C i^{D}$ mutation (Fig. $\mathrm{BB}$ ) and the recessive $\mathrm{Ce}$ mutation (Fig. 1C).

\section{Cloning sequences from the $\mathrm{ci}^{\mathrm{D}}-\mathrm{Ce}$ region}

The $c i^{D}$ mutation causes a dominant wing vein defect in addition to the recessive segmentation defect. The dom- 


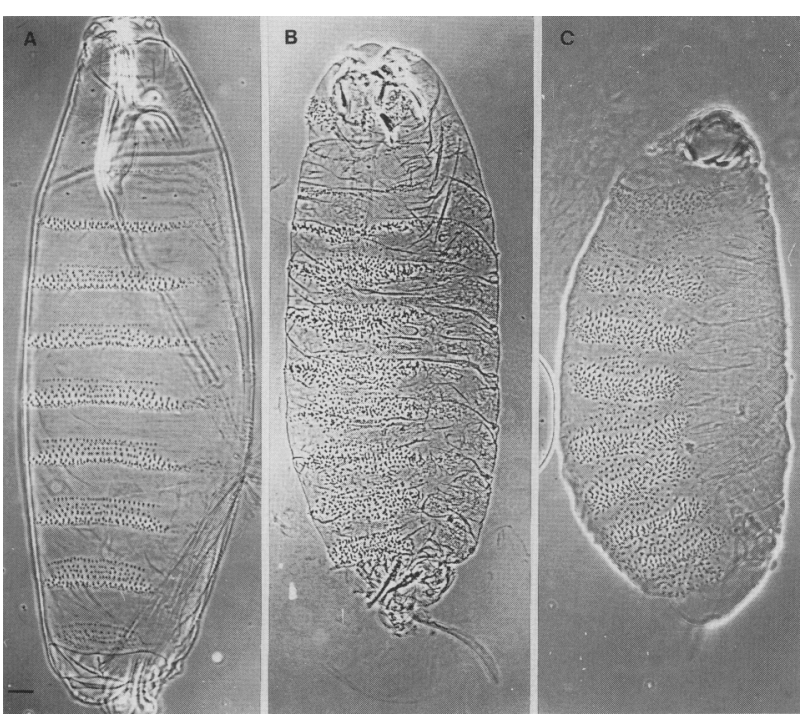

Figure 1. Ventral surface of Drosophila embryos photographed under phase contrast (anterior up). (A) Wild type. The repeating pattern of segmentation is manifested by the alternation of clear cuticle in the posterior half of each segment with the denticle belts that are located in the anterior half of every segment. $|B| c i^{D} / \mathrm{Ci}^{D}$. The clear cuticle of the posterior half of each segment is eliminated and replaced with an apparent mirror image duplication of the denticle belts. $(C) \mathrm{Ce} / \mathrm{Ce}$. The clear cuticle of the posterior half of every segment is deleted as is the anterior margin of the adjacent segment. Obvious polarity reversals are not as evident, and many of the denticles appear to be pointed at random. The embryo is much smaller than wild type. Bar, 25 $\mu \mathrm{m}$.

inant wing vein alteration is a gain-of-function defect because flies heterozygous for deficiencies in the region do not have the wing vein defect, and the mutant phenotype is fully penetrant in $\mathrm{ci}^{D} /+/+$ flies (Lindsley and Grell 1968). Our strategy for cloning sequences from the $\mathrm{Ci}^{D}-\mathrm{Ce}$ region was to revert the dominant wing vein defect by insertion of a P element (Bingham et al. 1982). We isolated three independent P-element revertant lines ( $c i^{D R P}$; see Materials and methods). Hybridization in situ to polytene chromosomes from these lines revealed that each line has a P-element insertion at 101F, the cytological location of $\mathrm{ci}^{D}$ and $\mathrm{Ce}$. (Lindsley and Grell 1968; data not shown). Genomic libraries were constructed from each of the $c i^{D R P}$ lines, and they were screened with a P-element-containing fragment from the plasmid p6.1 (Rubin and Spradling 1982). P-element-containing clones from the first line were hybridized in situ to polytene chromosomes from wild-type Oregon- $R$ (Ore-R) flies. Ore- $R$ is an $M$ strain that does not contain $P$ elements, and therefore, the site of hybridization identifies the cytological origin of the sequences flanking the P-element insertion. Two clones hybridized to $101 \mathrm{~F}$. The genomic region next to the P-element insertion in these clones and a P-element probe were used to isolate clones from the other two lines. By restriction analysis of the clones from the three lines and genomic blot analysis of DNA from the corresponding flies, we determined that the P-element insertions all occurred in the same $0.6-\mathrm{kb}$ EcoRI restriction fragment. An independent insertion of a P-element containing the $\beta$-galactosidase gene into this region has been obtained by Eaton and Kornberg (1990). Using a unique 5-kb EcoRI fragment (Fig. 2) located next to the P-element insertion, we isolated a number of wild-type $\lambda$ clones and one cosmid clone. A restriction map of the region around the P-element insertions is depicted in Figure 2. The genomic clones contained repetitive sequences, which, when used to probe polytene chromosomes, variously hybridized to the chromocenter and the bases of the five chromosome arms. The repetitive elements made chromosome walking extremely difficult and regularly caused DNA rearrangements in the cloned sequences. Our restriction map of the $c i^{D}-C e$ region was confirmed by probing blots of digested genomic DNA.

\section{The P-element insertions are in the $\mathrm{ci}^{\mathrm{D}}-\mathrm{Ce}$ region}

To determine whether the P-element insertions occurred within or near the $\mathrm{ci}^{D}$ or $\mathrm{Ce}$ genes, we examined the effect of the $c i^{D R P}$ mutation on embryonic segmentation. Homozygous $c i^{D R P}$ embryos have a segmentation defect very similar to that of $c i^{D}$ embryos. The $c i^{D}$ and $\mathrm{Ce}$ mutations partially complement each other; $\mathrm{Ci}^{D} / \mathrm{Ce}$ heterozygotes develop into normally segmented viable larvae that die as pupae (Orenic et al. 1987). The $c i^{D R P}$ mutations fail to complement $\mathrm{Ce}$, and $\mathrm{ci}^{D R P} / \mathrm{Ce}$ embryos have a segment polarity defect resembling $C i^{D}$ mutants, although their phenotype is slightly weaker. This failure of $c i^{D R P}$ to complement the $C e$ mutation indicates that the P-element insertions affect the embryonic $\mathrm{Ce}$ function. To characterize further the cloned region, we examined its structure in various mutants. The $c i^{1}$ mutation causes a recessive wing vein defect similar to that of $c i^{D}$ and is known to map near the $c i^{D}$ and $C e$ genes (Lindsley and Grell 1968). The $\mathrm{ci}^{1}$ mutation is suppressible by suppressor of Hairy wing [su(Hw)]. Mutations that are suppressible by $s u(\mathrm{Hw})$ are in almost all cases caused by insertion of the transposable element gypsy (Modolell 1983). We cloned the genomic sequences containing the gypsy insertion from $c i^{1}$ mutant flies and mapped the insertion that causes the $c i^{1}$ mutation to a 6-kb BgllI fragment near the P-element insertion (Fig. 2). Genomic blot analysis of DNA from flies heterozygous for the $c i^{D}$ or $C e$ mutations shows that these flies carry the wild-type 6-kb BgIII fragment and also an altered fragment. In $c i^{D}$ flies, the altered fragment migrates at $\sim 10 \mathrm{~kb}$ and in $\mathrm{Ce}$ at $\sim 9 \mathrm{~kb}$. These altered mobilities may be due to polymorphisms in the original wild-type strains. However, we have cloned sequences corresponding to the $c i^{D}$ mutation, and it appears that this allele is probably a small cytologically invisible inversion (see Fig. 2, legend).

\section{Identification of the $\mathrm{ci}^{\mathrm{D}}$ transcript}

Several transcripts in the region have been mapped and their respective cDNA clones isolated. They are shown 


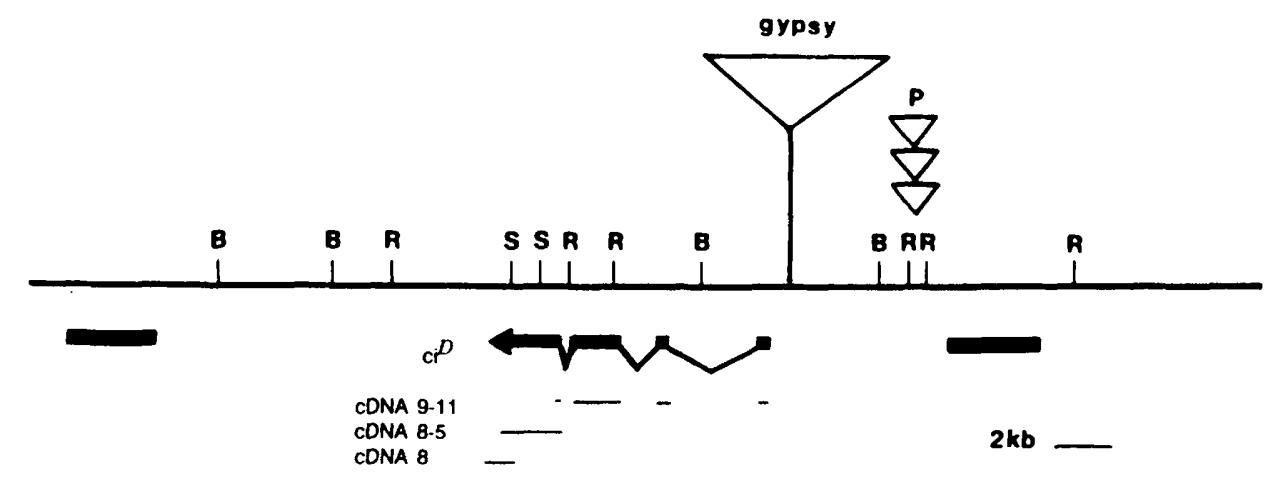

cosmid 4-1

Figure 2. Map of the $c i^{D}-C e$ region. Independent P-element insertions occurred within the same $0.6-\mathrm{kb}$ EcoRI fragment in all three lines. Black bars signify transcripts. The transcript to the right of the P-element insertions was ruled out as either the $c i^{D}$ or $C e$ transcript because it is maternally contributed to the egg. Black bar with arrow head indicates the $c i^{D}$ transcript and the direction of transcription. cDNA clones representative of this transcript are shown below it. The breaks indicate the location of introns that have been determined by the hybridizing of cDNA clones to genomic clones and by comparison of the cDNA and genomic restriction maps. There are two more small introns (of $\sim 50$ and $100 \mathrm{bp}$ ) within the $1.5-\mathrm{kb}$ EcoRI genomic fragment to which part of cDNA 9-11 maps. The 5 '-most exon occurs within a 6-kb BgIII fragment that is $1 \mathrm{~kb}$ away from the P-element insertions and that contains the region of insertion of the gypsy element. We cloned this region from the $c i^{D}$ mutant chromosome and showed that the 0.6 -kb $E c o R I$ fragment that is the site for the P-element insertions is now adjacent to new sequences. The new sequences originate from the base of the fourth chromosome. Because the $c i^{D}$ mutation was generated by X-irradiation, the $c i^{D}$ chromosomal lesion is probably either a deletion or small inversion. The event does not appear to be a deletion because the sequences that were adjacent to the $0.6-\mathrm{kb}$ fragment and contain the $c i^{D}$ transcript are still present as determined by scanning densitometry of genomic Southern blots probed with $c i^{D}$ cDNA and genomic clones. Representative genomic clones that encompass the region are shown below the map. (B) BglII; (R) EcoRI; (S) SphI.

on the map in Figure 2. We identified one of these transcripts as the $c i^{D}$ transcript (Fig. 2). The identification of this transcript was based on its location relative to mutations in the $c i^{D}$ gene, its temporal pattern of expression, its spatial pattern of expression in wild-type embryos, and its absence in homozygous $\mathrm{Ci}^{D}$ embryos.

We have three cDNA clones (cDNAs 8, 8-5, and 9-11; Fig. 2) that span most of the putative $c i^{D}$ transcription unit. The transcript has two small $5^{\prime}$ exons that map to the 3-kb EcoRI-BglII and the 6-kb BglII fragments, respectively. The $6-\mathrm{kb}$ BglII fragment contains the $c i^{1}$ insertion, is $1-\mathrm{kb}$ away from the $c i^{D R P}$ insertions, and its mobility is altered in chromosomes carrying the $c i^{D}$ and $\mathrm{Ce}$ mutations. The bulk of the coding region lies within a 6-kb EcoRI fragment some $12 \mathrm{~kb}$ from the sites of the $c i^{D R P}$ and $c i^{1}$ insertions.

We have shown that neither $c i^{D}$ nor $C e$ has a maternal contribution (Orenic et al. 1987), thus, we expect the $c i^{D}$ and $\mathrm{Ce}$ transcripts to be present only after the zygotic genome is activated at $2 \mathrm{hr}$ of development (Anderson and Lengyel 1981). Figure 3 displays a developmental Northern blot probed with cDNA 8, a 1-kb cDNA clone containing $3^{\prime}$ sequences of the putative $c i^{D}$ transcript (Fig. 2). cDNA 8 detects a $4.6-\mathrm{kb}$ transcript that is most abundantly expressed between 5 and $8 \mathrm{hr}$ of development. There is little or no hybridization of this cDNA to RNA from 0- to 2-hr embryos. Expression is reduced after $8 \mathrm{hr}$, but it increases again during the pupal stage.
This temporal pattern of expression is consistent with that seen in the four zygotic segment polarity genes $(e n$, $w g, g s b, p t c$ ) that have been cloned and analyzed (Fjose et al. 1985; Kornberg et al. 1985; Bopp et al. 1986; Baker 1987; Baumgartner et al. 1987; Hooper and Scott 1989; Nakano et al. 1989|.

Because the temporal pattern of expression of this cDNA appeared to be appropriate, we were interested in determining its spatial pattern of expression. Because the $c i^{D}$ and $C e$ mutations cause specific defects in a subregion of every segment, it seemed likely that, like the other zygotic segment polarity genes en, $w g, g s b$, and ptc, (Fjose et al. 1985; Kornberg et al. 1985; Bopp et al. 1986; Baker 1987; Baumgartner et al. 1987; Hooper and Scott 1989; Nakano et al. 1989) their products would be expressed in a segmentally repeating pattern. To test this, we performed in situ hybridizations to sections and whole mounts of 4-8 hr embryos. The sections were probed with ${ }^{35} \mathrm{~S}$-labeled sense and antisense RNA probes from cDNA 8 . There was little or no hybridization with the sense probe (data not shown). The antisense probe hybridized to the embryos in a series of broad segmentally repeating stripes (Fig. 4G,H). The same result was obtained on the whole mounts in situs. The whole mounts were probed with digoxigenin-labeled cDNA 8, and hybridization was detected with an alkaline phosphatase-coupled antibody against digoxigenin (Fig. 5A Tautz and Pfeifle 1989). 


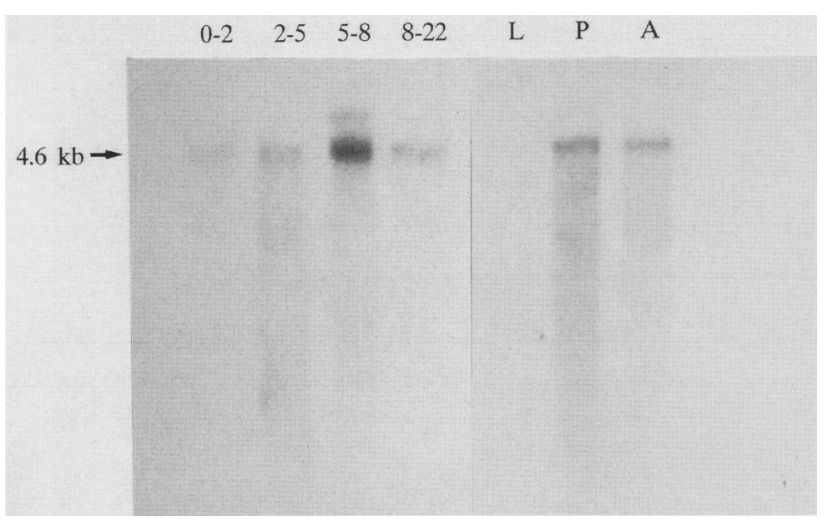

Figure 3. Temporal expression pattern of $c i^{D}$. Developmental Northern blot hybridized with a 1-kb 3' cDNA clone (cDNA 8). Poly $(\mathrm{A})+$ RNA was purified from 0- to 2-, 2- to 5-, 5- to 8-, and 8to $22-\mathrm{hr}$ embryos and from larvae, pupae, and adults $110 \mu \mathrm{g}$ loaded per lane). The small amount of hybridization seen with cDNA 8 in the $0-$ to 2 -hr lane is due to retention of eggs. As a control, we probed a similar blot with an en cDNA and also obtained a small amount of hybridization in the 0 - to 2 -hr lane. We expected to see little or no hybridization between 0 and $2 \mathrm{hr}$ because $c i^{D}$ is known not to have a maternal contribution. The most abundant time point of expression was between 5 and 8 hr. The level of expression dropped between 8 and $22 \mathrm{hr}$ but it rose again in pupal and adult stages suggesting that $c i^{D}$ has a function in adult as well as embryonic development.

To determine whether cDNA 8 corresponds either to the $c i^{D}$ or the $C e$ gene, we hybridized it to sections of homozygous $\mathrm{Ce}$ and $\mathrm{ci}^{D}$ embryos. The hybridization pattern of cDNA 8 in Ce mutants appeared the same as in wild-type embryos. In homozygous $c i^{D}$ embryos, however, the striped pattern of expression was replaced by a low level of hybridization that was slightly above background and dispersed uniformly over the embryo (Fig. $4 \mathrm{~K}, \mathrm{~L})$. As a control, adjacent sections were probed simultaneously with cDNA 8 and a $g s b-d$ probe. Only the $g s b-d$ stripes were apparent in these embryos (data not shown). In addition, we examined the expression pattern of cDNA 8 in homozygous $M^{62 f}$ embryos $\left(M^{62 f}\right.$ is a deficiency in the $c i^{D}-C e$ region) and as expected, no hybridization above background was detected. These data demonstrate that cDNA 8 corresponds to the $c i^{D}$ transcript.

\section{Relationship between $\mathrm{ci}^{\mathrm{D}}$ and $\mathrm{Ce}$}

Genetic analysis of the region has shown that $c i^{D}$ and $C e$ are either two tightly linked genes or that they represent complementing alleles of a single locus (Hochman 1971, 1973, 1976; Orenic et al. 1987). Evidence cited above suggests that cDNA 8 is derived from the $c i^{D}$ transcript. We have not found an additional independent transcription unit for the $\mathrm{Ce}$ gene; therefore, we believe that the two functions identified as $\mathrm{Ci}^{D}$ and $\mathrm{Ce}$ may be encoded on the same transcript or are the products of differential splicing. In addition to the $4.6-\mathrm{kb}$ transcript, cDNA 8 weakly hybridizes to a second larger transcript (Fig. 3). This second transcript is detected with approximately equal intensity by cDNA 9-11, which contains the $5^{\prime}$ half of the $c i^{D}$ transcript (data not shown). It is possible that this second alternatively spliced product is the $C e$ transcript. We have not yet been able to isolate cDNA sequences specific to the alternative transcript, and this has prevented us from studying it in detail. However, sectioned wild-type embryos probed with cDNA 9-11 have essentially the same pattern of hybridization as embryos probed with cDNA 8 (data not shown). In our subsequent studies, we used cDNA 8 as our probe because it gives the cleanest hybridization signals, and the transcript it recognizes is specifically eliminated in $\mathrm{ci}^{D}$ mutants.

\section{Spatial pattern of expression of $\mathrm{ci}^{\mathrm{D}}$ throughout development}

Figure 4, A and B shows a stage 4 embryo; there is no detectable expression of the $c i^{D}$ transcript at this stage. The transcript is initially detected during early cellular blastoderm stage (stage 5, Campos-Ortega and Hartenstein 1985; Fig. 4C,D). It is distributed uniformly throughout the cortical region on the dorsal surface between $\sim 20$ and $90 \%$ egg length. During cellular blastoderm, the transcript extends ventrally until it becomes uniformly distributed throughout the embryo. Expression is almost uniform in the gastrulating embryo (Fig. $4 \mathrm{E}, \mathrm{F})$ and until the end of the fast phase of germ-band elongation except for reduced expression in the head (stages 6-8). At the end of the fast phase of germ-band elongation (end of stage 8), expression is eliminated in a region approximately one-quarter the width of every segment (Fig. 4G, H).

At the end of the fast phase of germ-band extension the expression pattern resolves into 15 broad segmentally repeating stripes that are within parasegments $0-14$ (Fig. 4G,H). Stripe 0 appears to be about twice the width of the other stripes and probably includes primordia corresponding to the intercalary or hypopharyngeal segment and the mandibular segment. (Fig. 4G, H). Expression is also observed in the hindgut primordium and in the head region over what probably corresponds to the procephalic lobe. At the beginning of stage 10, the stomodeal invagination appears. Labeling is observed at this stage in the tissue on either side of the invagination but not within it.

The transcript accumulates in the ectoderm, nervous system, and mesoderm during germ-band elongation, except for stripe 0 , which appears to be restricted to ectoderm. Between the end of germ-band elongation and the beginning of germ-band retraction, the transcript becomes gradually restricted to the ectoderm. It disappears initially from the developing nervous system and fades more gradually within the mesoderm (Fig. 4I,J). By the time germ-band retraction is completed, the stripes of expression can be seen primarily in the ectoderm, and they are much reduced in intensity relative to that during germ-band elongation. There is very little expression in the embryo by the time dorsal closure is completed (stage 15), although some residual labeling remains over the foregut and hindgut. 


\section{Orenic et al.}
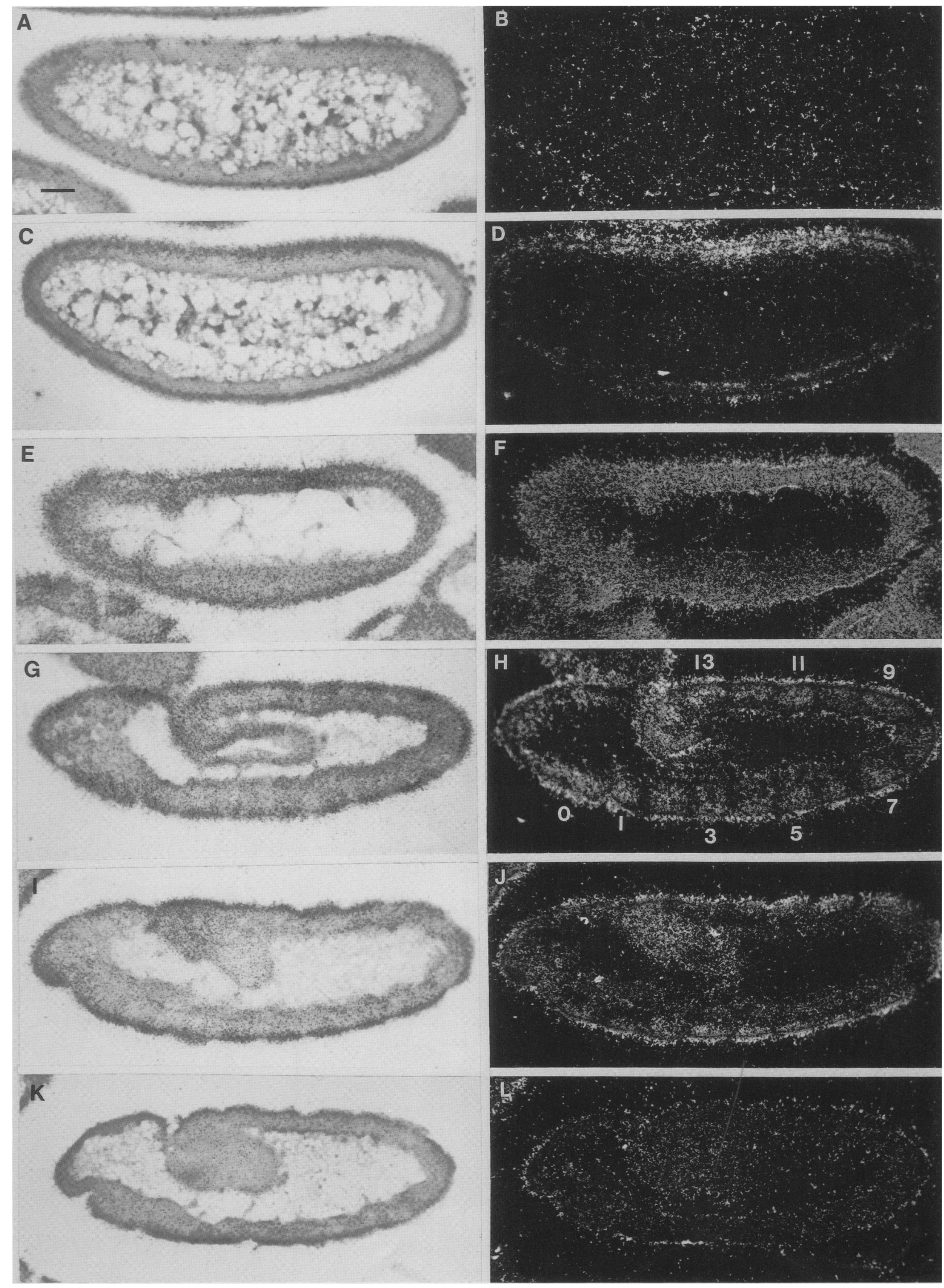

Figure 4. (See facing page for legend.) 


\section{Registration of the $\mathrm{ci}^{\mathrm{D}}$ stripes of expression}

To determine the registration of the $c i^{D}$ stripes of expression, their location was compared to the position of the parasegmental grooves. In Figure 5, A and B are photographs at lower and higher magnification of a stage 11 embryo at which time the parasegmental furrows appear. This whole-mount embryo was labeled with cDNA 8 using a nonradioactive detection system /Tautz and Pfeifle 1989; as modified by Oh and Edgar, pers. comm.; see Materials and methods). These figures demonstrate that $c i^{D}$ expression is in a stripe anterior to the parasegmental furrow (arrows). It also shows that the stripes are $8-10$ cells wide, and the interstripe region is $2-3$ cells wide.

To confirm the registration, we performed hybridizations onto sections of germ-band extended embryos simultaneously with the $c i^{D}$ cDNA and with an en or $w g$ probe. At this stage, the $c i^{D}$ transcripts are expressed in stripes covering approximately three-quarters of each segment. en is expressed in the posterior quarter of every segment (Fjose et al. 1985; Kornberg et al. 1985). In embryos hybridized with both $c i^{D}$ and $e n$, hybridization was uniform throughout the segment (data not shown). This result suggests that $c i^{D}$ and $e n$ have reciprocal patterns of expression and that the region not expressing $\mathrm{Ci}^{D}$ lies in the posterior quarter of the segment. To confirm this, cDNA 8 and a wg probe (Baker 1987) were hybridized to the same sections. $w g$ is expressed in the third quarter of every segment just anterior to the parasegmental boundary and the en stripe of expression. One can see in Figure 5C that the posterior edge of the $\mathrm{ci}^{D}$ stripe has an augmented hybridization signal that is due to the expression of $w g$ within this region. This indicates that $c i^{D}$ is expressed in the anterior three-quarters of the segment in germ-band extended embryos. Figure $5 D$ shows expression of the $c i^{D}$ transcript in a late germband retracted embryo (stage 13) in which the segmental grooves are apparent. At this stage, the anterior boundary of the stripe of expression appears to coincide with the anterior segmental boundary. Comparison of this pattern with the en pattern at this stage (Kornberg et al. 1985) shows that their patterns appear to be reciprocal. The registration of the $c i^{D}$ stripes of expression relative to the $e n$ and $w g$ stripes and to the region of the segment that is affected in $c i^{D}$ mutants is summarized in Figure 6.

\section{$\mathrm{ci}^{\mathrm{D}}$ encodes a zinc-finger DNA-binding protein}

We sequenced three partial cDNA clones and were able to determine the entire coding sequence of the $\mathrm{ci}^{D}$ messenger RNA (Fig. 7). The putative initiator methionine was assigned on the basis that it is preceded by termination codons in all three reading frames; it has three of four matches with the Drosophila initiation consensus sequence (Cavener 1987); and it is followed by a long uninterrupted open reading frame. The $3^{\prime}$ cDNA ends with a run of 16 adenine residues, but this is not preceded by a canonical $\mathrm{A}_{2} \mathrm{UA}_{3}$ sequence. The most similar sequence, $\mathrm{AU}_{2} \mathrm{~A}_{3}$, was found 28 nucleotides before the poly $(A)$ stretch, and this may function as a polyadenylation signal.

Analysis of the coding sequence of the $c i^{D}$ transcripts shows that $c i^{D}$ encodes a protein domain with sequence similarity to the zinc-finger domain of the Xenopus transcription factor TFIIIA. TFIIIA, which is required for correct transcription by RNA polymerase III of the $5 \mathrm{~S}$ RNA genes of Xenopus, is known to bind both DNA and 5S RNA (Brown et al. 1985; Miller et al. 1985). This finger motif has also been identified in genes that are most probably polymerase II transcription factors. These include the yeast ADRI gene (Hartshorne et al. 1986), the human SP1 gene (Kadonaga et al. 1987), and several Drosophila genes including serendipity (sry) (Vincent et al. 1985), snail (Boulay et al. 1987), glass (Moses et al. 1989), and two of the gap genes, Kruppel (Kr) (Rosenberg et al. 1986) and hunchback (hb) (Tautz et al. 1987).

The zinc-finger domain (shown in bold in Fig. 7) of $\mathrm{ci}^{D}$ consists of five tandemly repeated units composed of 30-33 amino acid residues. A direct amino acid comparison between the finger domains of $c i^{D}$, TFIIIA, and $K r$ (Miller et al. 1985; Rosenberg 1986) is shown in Figure $8 \mathrm{~A}$. The repeats in $\mathrm{Ci}^{D}$ conform well to the finger consensus sequence (Miller et al. 1985; Berg 1986):

$\begin{array}{lllllll}1 & 6 & 10 & 16 & 19 & 24 & 30 \\ \mathrm{C}-\mathrm{X}_{2-4}-\mathrm{C}-\mathrm{X}_{3}-\mathrm{F}-\mathrm{X}_{5}-\mathrm{L}-\mathrm{X}_{2}-\mathrm{H}-\mathrm{X}_{3-4}-\mathrm{H}-\mathrm{T}-\mathrm{G}-\mathrm{X}_{3}-\mathrm{Y} / \mathrm{F}-\mathrm{X}\end{array}$

with two exceptions. Phe-10 (F-10) is highly conserved in $K r$ and TFIIIA domain repeats. In repeats 2,3 , and 5 of $c i^{D}$, it is replaced by Glu, Tyr, and Tyr respectively. Deviation from this conserved residue is also seen in the $h b$ repeats, and in two cases, it is replaced by the aromatic amino acid Tyr. Divergence from the consensus sequences also occurs in repeats 2 and 4 at Leu-16 (L-16), another residue that is highly conserved in TFIIIA and $\mathrm{Kr}$.

The number of amino acid residues between Cys-3 (C-3) and C-6 is usually either 2 or 4 . In the $c i^{D}$ finger repeats, there are 4 residues as occurs in TFIIIA, whereas in the Drosophila finger proteins $K r, h b$, and sry there are 2 residues. Conservation is also observed in the residues that link the finger repeats. This linker region corresponds to amino acids $25-31$ in the consensus sequence shown above. In Figure $8 \mathrm{~A}$ they are the last 7-9

Figure 4. Pattern of $c i^{D}$ expression in wild-type and mutant embryos. Eight-micron wax sagittal sections (with the exception of the section in $E$ and $F$, which is a slightly oblique sagittal section) of embryos at various stages of development were hybridized with an ${ }^{35}$ S-labeled antisense RNA probe from cDNA 8 (see Fig. 2). Anterior is to left; dorsal is up. $(A, C, E, G, I$, and $K)$ Bright-field photomicrographs. $(B, C, F, H, I$, and $L)$ Dark-field photomicrographs. $(A$ and $B)$ Syncytial blastoderm embryo. No specific labeling is detected at this stage. $(C$ and $D)$ Early cellular blastoderm embryo. $(E$ and $F)$ Gastrulating embryo. $(G$ and $H)$ Germ-band extended embryo. $(I$ and $I$ Stage 11 embryo. $(K$ and $L)$ Bright-field and dark-field photomicrographs of a homozygous $c i^{D}$ embryo. Very little hybridization is observed in this embryo, indicating that cDNA 8 corresponds to the $c i^{D}$ transcript. Bar, $25 \mu \mathrm{m}$. 

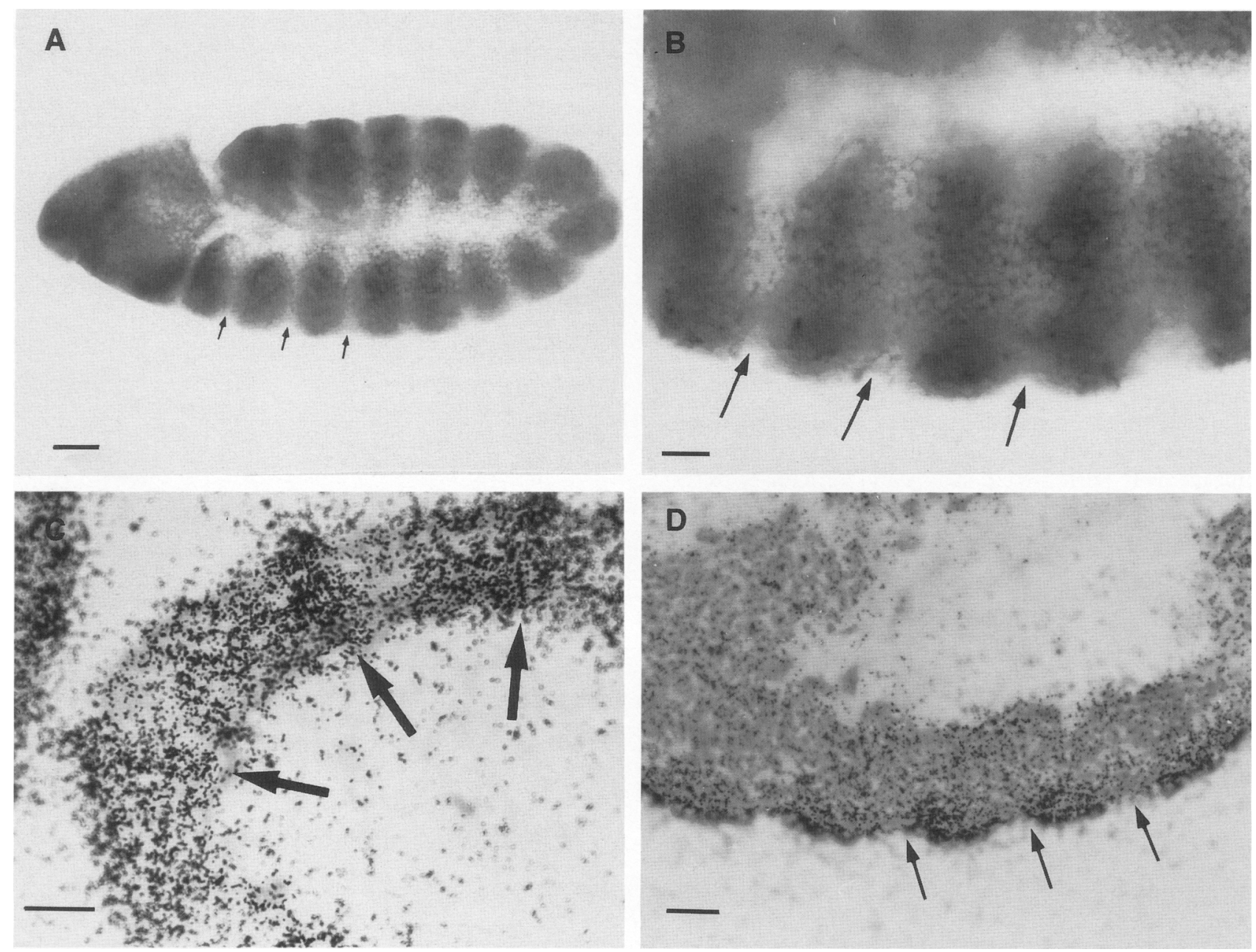

Figure 5. Bright-field micrographs depicting the registration of $c i^{D}$ stripes of expression. $\mid A$ and $B \mid$ Whole-mount embryo in which the Genius detection system was used to detect $c i^{D}$ transcripts (see Materials and methods). This method provides higher resolution than the standard in situ hybridization protocol. Anterior is to left and dorsal is up. $(A \mid$ Stage 11 embryo in which the parasegmental furrows are apparent (arrows). (B) A higher magnification of the same embryo shown in $A$. The arrows indicate the parasegmental furrows, and they indicate the same segments that are indicated in $A$. Anterior is to left, and dorsal is up. $(C)$ Three segments of a germ-band extended embryo hybridized simultaneously with ${ }^{35} \mathrm{~S}$-labeled riboprobes from cDNA 8 and the wg cDNA. Arrows indicate region of expression of both $c i^{D}$ and $w g$. This photograph shows that in embryos probed with both $c i^{D}$ and $w g$, there is no hybridization above background levels detectable in the posterior quarter of the segment, which is where en is normally expressed. The region depicted is the extended germ band. Anterior of the embryo is to right; dorsal is up. (D) Stage 13 embryo. Anterior is to left, and dorsal is up. Bar, $25 \mu \mathrm{m}$ in $A ; 10 \mu \mathrm{m}$ in $B, C$, and $D$.

amino acids of each finger repeat shown. The linker regions between repeats 2 and 3 and repeats 3 and 4 are identical or nearly identical to the linker region in the TFIIIA consensus sequence and to the $4 \mathrm{Kr}$ linker regions, and the linker region between repeats 4 and 5 is the same in 4 of 6 residues. Like TFIIIA and $K r$, the linker regions between the $c i^{D}$ finger repeats are 7 amino acids in length with the exception of the one between repeats 1 and 2, which has 9 amino acids. In the majority of repeats within the finger proteins, there are 12 amino acids between C- 6 and His-19 $(\mathrm{H}-19)$; this is true for $\mathrm{Ci}^{D}$ with one exception; in repeat 2 the length is 15 amino acids.

A search of the EMBL/GenBank Sequence Data Library revealed that, of the zinc-finger proteins, $c i^{D}$ has the highest degree of similarity to the human protein GLI, which has been classified under the $K r$ family of zinc-finger proteins and has 5 repeats of 30-33 amino acids (Kinzler et al. 1987, 1988; Fig. 8B). GLI was identified initially on the basis of its 75 -fold amplification in a human glioblastoma. It was later found to be amplified in other human glioblastomas, and it is expressed in embryonal carcinoma cells but not in most adult tissues. The sequence similarity between $c i^{D}$ and $G L I$ is striking. There is $54.3 \%$ identity in a 278 -amino-acid overlap, which begins 13 amino acids before the first zinc finger and extends $\sim 100$ amino acids beyond the last zinc finger. Between the twelfth amino acid residue of the second repeat and up to 1 residue after the end of the fifth repeat (108 amino acids) there are only seven mis- 


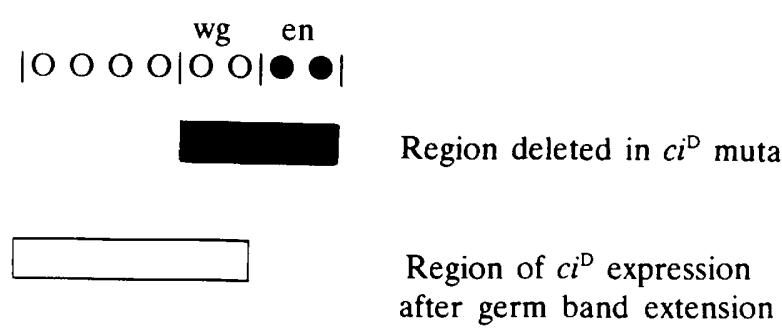

Figure 6. Summary diagram of registration of $c i^{D}$ stripes relative to expression of $w g$ and $e n$ and to the region of the segment affected in $c i^{D}$ mutant embryos. $c i^{D}$ is expressed in the anterior three-quarters of the segment after germ-band extension in a pattern that appears to be reciprocal to the en expression pattern. This expression pattern is not consistent with the defects seen in $\mathrm{ci}^{D}$ mutants in which the posterior half of every segment is affected.

matches, three of which are conservative substitutions. This corresponds to $93 \%$ identity. Amino acid residues that are not normally conserved $\{2-4 ; 7-9 ; 11-15$; 20-23 in the consensus sequence) among the zinc-finger proteins are conserved or have conservative substitutions between $c i^{D}$ and $G L I$. The linker region between repeats 1 and 2 , which in $c i^{D}$ is 9 amino acids in length (rather than 7 as in the other repeats), is the same length in $G L I$, and there are four matches and five conservative substitutions. The unusually long 15-amino-acid stretch between $\mathrm{C}-6$ and $\mathrm{H}-19$ in repeat 2 is also 15 amino acids in length in repeat 2 of GLI, and they match in the last 10 amino acids. The number of amino acids between the two His residues in $c i^{D}$ is 3 in repeats 2 and 3 and 4 in repeats 1,4 , and 5 ; the same configuration is observed in GLI.

Evidence indicates that the finger proteins function in regulation of transcription. TFIIIA and SP1 have been shown to bind DNA specifically and to require zinc for binding (Hanas et al. 1983; Smith et al. 1984; Kadonaga et al. 1987). The zinc-finger domain is also essential for transcriptional activation of $\mathrm{ADH} 2$ by ADRI (Blumberg et al. 1987). Thus, it is reasonable to conclude that the presence of the zinc-finger repeats in the $c i^{D}$ cDNA strongly suggests that one function of $c i^{D}$ is in transcriptional regulation.

\section{Discussion}

\section{Cloning the $\mathrm{ci}^{\mathrm{D}}$ gene}

Sequences from the $c i^{D}-C e$ region were cloned by use of P-element insertions to revert the dominant wing vein defect caused by the $c i^{D}$ mutation. Several lines of evidence indicate that the P-element insertions we isolated are within or near the $c i^{D}-C e$ region. The three independent P-element insertions all occurred within a $0.6-\mathrm{kb}$ EcoRI fragment. We examined the structure of the region around the P-element insertions in several mutations from the $c i^{D}-C e$ region. All the alterations we observe occur within the $6-\mathrm{kb} B g l I I$ fragment that is $1 \mathrm{~kb}$ away from the $0.6-\mathrm{kb}$ EcoRI fragment containing the Pelement insertions. In genomic sequences from $c i^{D}$ and
$\mathrm{Ce}$ flies, the mobility of the 6-kb BglII fragment is altered. Although it is possible that these are polymorphisms, analysis of sequences cloned from the $\mathrm{Ci}^{D}$ chromosome in this region suggests that the $c i^{D}$ mutation is caused by a small cytologically invisible inversion. Furthermore, the $c i^{D R P}$ chromosomes, unlike the $c i^{D}$ mutation, fail to complement the $\mathrm{Ce}$ mutation, indicating that the P-element insertions are affecting $\mathrm{Ce}$ function. This is consistent with the results of the genetic analysis of the $\mathrm{Ci}^{D}-\mathrm{Ce}$ region, which indicates that $\mathrm{Ci}^{D}$ and $\mathrm{Ce}$ are very tightly linked.

We mapped transcripts in the region and identified a $4.6-\mathrm{kb}$ transcript as the $c i^{D}$ transcript. The $5^{\prime}$-most exon of this transcript maps within the 6-kb BglII fragment. Thus, because the P-element insertions are within the $0.6-\mathrm{kb}$ EcoRI fragment $5^{\prime}$ to this, it is very likely that they are within $5^{\prime}$ regulatory sequences of the $c i^{D}$ gene. The transcript is not expressed until the cellular blastoderm stage (Fig. 4A-D), which is consistent with our finding that there is no maternal contribution of the $c i^{D}$ gene product to the developing oocyte. It is most abundantly expressed between 4 and $6 \mathrm{hr}$ of development, which is similar to the temporal expression patterns of en, gsb, wg, and ptc (Fjose et al. 1985; Kornberg et al. 1985; Bopp et al. 1986; Baker 1987; Baumgartner et al. 1987; Hooper and Scott 1989; Nakano et al. 1989|. Expression of $\mathrm{Ci}^{D}$ drops off after $11 \mathrm{hr}$ of development, but is resumed in late larval stages, pupae, and adults, implying that $c i^{D}$ may function in adult development as well as in embryonic development. Consistent with this, Eaton and Kornberg (1990) show in this issue that the $c i^{D}$ transcript is expressed specifically in the anterior compartment of imaginal discs. Because $c i^{D}$ is a zygotic gene, we expected that the $c i^{D}$ transcript might be expressed in a periodic pattern. The $4.6-\mathrm{kb}$ transcript is expressed in segmentally repeating stripes, although the stripes were broader than we would have expected, given the phenotype of the $c i^{D}$ mutation. The strongest evidence indicating that the $4.6-\mathrm{kb}$ transcript represents the $c i^{D}$ transcript is that this transcript is essentially absent in homozygous $c i^{D}$ mutants.

\section{Relationship between $\mathrm{ci}^{\mathrm{D}}$ and $\mathrm{Ce}$}

Genetic analysis of the $c i^{D}-C e$ region indicates that either $\mathrm{Ci}^{D}$ and $\mathrm{Ce}$ are two independent but tightly linked genes, or they represent mutations in a single complex locus. Because we have been unable to find an independent $\mathrm{Ce}$ transcript, we favor the hypothesis of intracistronic complementation. Several types of intracistronic complementation are possible. Protein subunits containing the $c i^{D}$ and $C e$ mutations could associate to form functional multimers. This seems unlikely, given the dramatic reduction in the level of the $c i^{D}$ mRNA in $c i^{D}$ mutants. A second possibility is that the $c i^{D}$ and $C e \mathrm{mu}$ tations affect expression of alternative products from a gene with differential splicing. We see two related transcripts at the $c i^{D}$ locus, which differ at least with regard to their $3^{\prime}$ ends. These two RNA species could be the products that encode the $c i^{D}$ and $C e$ functions, respec- 
TATAGGCCGGGTGAMATCATGTGGCTGTCCAGTAMCATTTATATTGTGMACATGTTGAGGCTGATGATTGTGCTGGTGGCCAGCATTTC 91 CAAGMAGGTGTTTTCATTGCATATTTGTGGTTGTATTGMATTTTAMTTGMATCTGATGTTCCACCCGTTGGACATMTTGATGGCACT 181 GTTACCGAGCTTGAAACGTCAGTTGGTGTGATGTTGGTTTATGCATGGTGATCCTGGTAMCAGTAGCCGCTGCAGCGACGGCAGCTGCT 271 CTCCTGGACGCTAMAMCTGCAATTCAGATACGCAMGAGGAMATATGTAGGTMCGCGTAGGCTCCATTTCATTAMGTTAGTCCACA 361 ACAAGATGACGTCGTTTATAMATTCAATTATCCTTTTAMATATATTACGTCGGCGTACATTCAMGATGTATTTCMTMCGCAC 451 GCATAATTCACTTTGATCGGCAMCTMAGATTAGMACTCTGTGATAMAGTGTTTTMATTAATATGTMATATTCATATCACTTMMTATTA 541 TAATGGTGTGAGCTTATGCGCTCGGCTTCCTAAGTATGMAGGTATCGCCAMTCTCACACGTATATTCATAMGATTATCAGTCCCTAA 631 GTAATATATTTATCACTMATATTAAGAGCGAACATGMAATCAGTTTTATAACACGCAGCATTCAMAMATATTGACTTGTCTCCGA \begin{tabular}{llllllllllllllllll}
$M$ & $K$ & $I$ & $F$ & $I$ & $T$ & $R$ & $S$ & $I$ & $Q$ & $K$ & $I$ & $L$ & $T$ & $L$ & $R$ \\
\hline
\end{tabular}

721 ATTCCCGGATACATGGMACAGTTGTATTCTCTTCACGMACTMTTCAGCTTCATCTTTTCACGATCCCTATGTCATTGTGCATCAGCA 811 TTCCATCTTGCCGGACTTGGTTTGGGATCAGCTGATTTTTTGGGCAGCCGAGGTTGAGCTCTTTGGTTAMCTGCATAATGCTGCTGTO

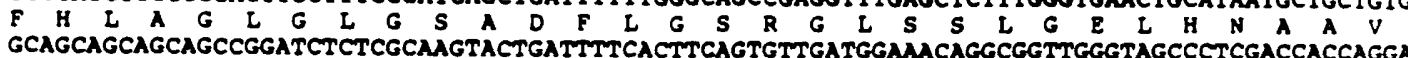

901 GCAGCAGCAGCAGCCGGATCTCTCGCAAGTACTGATTTTCACTTCAGTGTTGATGGMACAGGCGGTTGGGTAGCCCTCGACCACCAGGA

991 GGAAGTATACGTGCCAGCATMAGTCGCANACGAGCACTTTCGTCATCGCCTTATTCCGATTCATTTGATATTAMTTCAMTGATTCGATTT

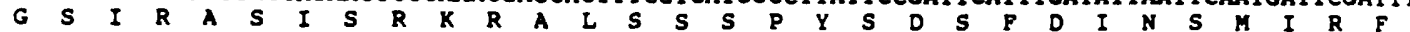

1081 TCGCCAMACTCTTTAGCCACAATTATGMCGGTTCTCGAGGMAGAGCGCGGCTAGTGGTTCTTACGGTCATATTTCTGCTACCGCCCTT $\begin{array}{llllllllllllllllllllllllllll}P & S & L & A & T & I & N & G & S & R & G & S & S & A & A & S & G & S & Y & G & H & I & S & A & T & A & L\end{array}$

1171 MATCCCATGTCTCATGTTCATTCA CCCGTCTGCA RAGATACAMGCTCATTTATTGCGTGCAMGTGCAGGTCTGTTAAMTCCGATGACA

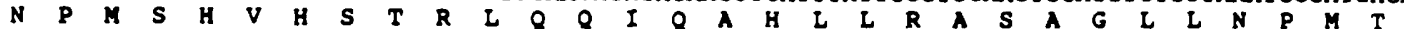

1261 CCACMCAAGTTGCTGCATCTGGATTTTCTATAGGCATATGCCMCCTCTGCTTCTTTGAGAGTGATGACGTACATCCTMATCTMGC $\begin{array}{lllllllllllllllllllllllllllll}P & Q & Q & V & A & A & G & G & S & I & G & H & M & P & T & S & A & S & L & R & V & N & D & V & H & P & N & L & S\end{array}$

1351 GATTCACATATCCAGATM CMACATCCCCAMCTGTTACAMAGGTGTAGCCAGGTCCСAGCGGCAGCATTCTCGTTGAMGMCTTAGAT DATGCAMGAGAGAMMAGGGACCCTTTAMGATGTTGTTCCCGAGCAGCCTTCATCGACATCTGGCGGCGTAGCACAAGTAGAGCCGAC

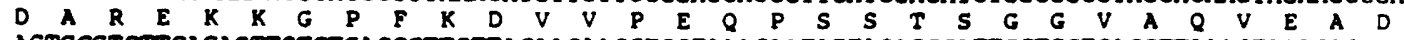

1531 AGTGCGTCTTCACAGTTGTCTGACCGTTGTTACACAACGTGGTAACAATATTACAGGCATTCCTGGTGACGTTAAGTAMACAGCCGC $\begin{array}{llllllllllllllllllllllllllllll}S & A & S & S & Q & L & S & D & R & C & Y & N & N & V & V & N & N & I & T & G & I & P & G & D & V & K & V & N & S & R\end{array}$

1621 TTGGATGAGTATATTAATTGCGGATCAATTCGATTCCGTCAMATGMTATGATTGTGCTMTGCTGATACTACGGATATCMGGATGAA $\begin{array}{lllllllllllllllllllllllllllllllll}L & D & E & Y & I & N & C & G & S & I & S & I & P & S & N & E & Y & D & C & A & N & A & D & T & T & D & I & K & D & E\end{array}$

1711 CCCGGAGATTTCATTGAACAMTTGTCATTGGCGTAGGTGTCGCATTGAGTTCATSACGCAGATGACTTGTTAMACATATAMTAAT GATCATATTCAMACAMACAGMAGCTTTGTCTGTCGATGGGMGATTGTACACGCGGTGMAMACCATTTAMGCGCAGTATATGCTT

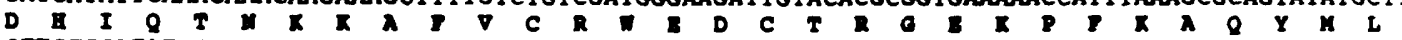

1891 GTTGTGCATATGCGGCGTCATACCGGTGAAAGCCACACANATGCACGTTTGAGGCTGCTTTMAGCATATTCACGTTTGGAMACCTG

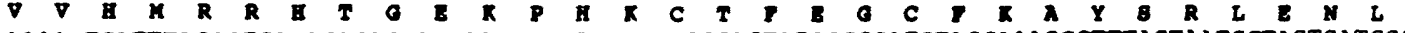

1981 AAAACTCATTTACGGTCACACACAGGAGAAAACCATACACTTGCGAGTATCCGgGaTGTAGCAMAGCCTTTAGTAATGCTAGTGATCGC

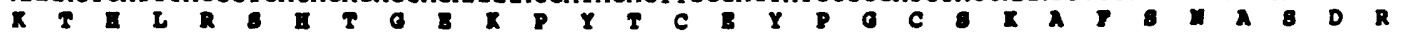

2071 GCAMGCATCAMATCGAACACACAGTMATGAGAMCCGTACATTTGTAMGCACCTGGATGCACAAACGTTACACCGACCCGAGCTCT

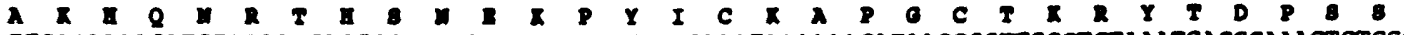

2161 TTGAGMMACATGTAMAMCAGTCCATGGAGCTGMATTTTATGCAMTMAMACATMGGGGTTGCCTCTMMTGACGCAMACTCTCGG

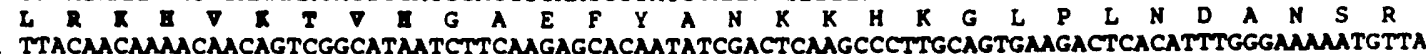
$\begin{array}{llllllllllllllllllllllllllllll}L & Q & Q & N & N & S & R & H & N & L & Q & E & H & N & I & D & S & S & P & C & S & E & D & S & H & L & G & K & M & L\end{array}$

2341 GGCACGTCTAGTCCTAGCATTAMATCTGMTCAGATATAGCTCATCAMACATCACTTAGTAMAGGAGTTCGAGCATCTGACAGTTTC

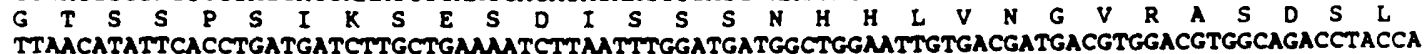
$\begin{array}{llllllllllllllllllllllllllllll} & T & Y & S & P & D & D & L & A & E & N & L & N & L & D & D & G & W & N & C & D & D & D & V & D & V & A & D & L & P\end{array}$

2521 ATTGTGTTACGTGCTATGGTAMTATTGGTACGGMATGCATCCGCCTCGACTATTGGAGGTTCTGTTTTGGCTAGGCACGGTTTAGA

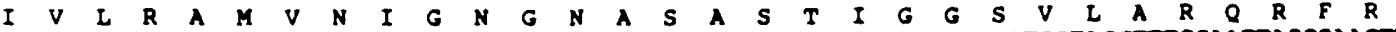

2611 GGTCGTCTTCAMACTMAGGTATAMATCAMGTACGATTATGCTTTGCMCATTCCAGMAGCMTCGTACCTTTGGATTAGCGMACTT

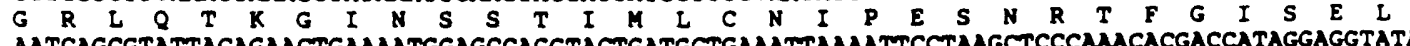

2701 AATCAGCGTATTACAGMACTGMAMTGGAGCCAGGTACTGATGCTGMATTMMATTCCTMAGCTCCCAMACACGACCATAGGAGGTATA

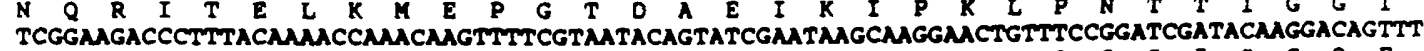

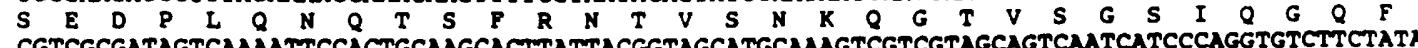

2881 CGTCGCGATAGTCAMATTCCACTGCAMGCACTTATTACGGTAGCATGCNMGTCGTCGTAGCAGTCAATCATS 0 V S S I

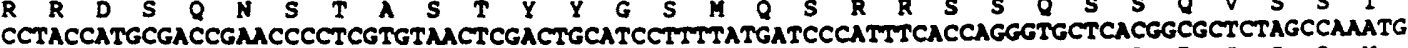

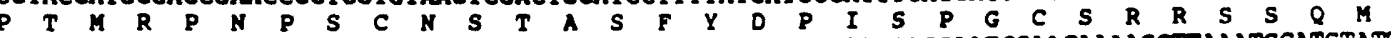

3061 TCAMTGGTGCTMACTGCAATTCATTTACTTCCACATCAGGACTACCCGTATTAMATMGGATCGMACAMAGCTTMATGCATGTATT

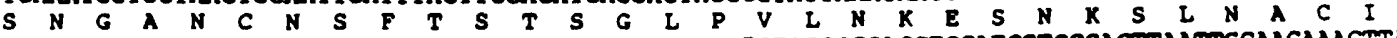

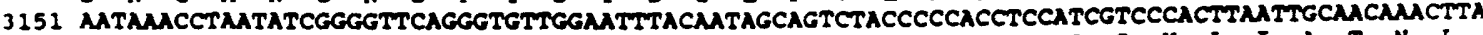

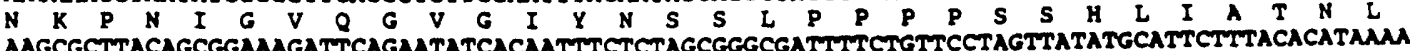

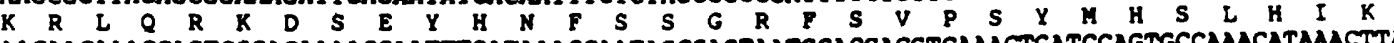

3331 AACAACAMCCAGTCGGAGMAMCGMATTTGATMAGCMATAGCGAGTMATGCACGACGTCAMCTGATCCAGTGCCNMCATAMCTTA

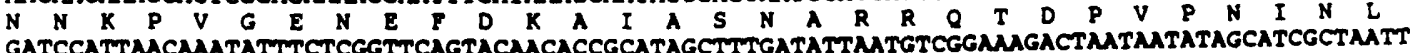
3421 GATCCATTAACAMATATTTCTCGGTTCAGTACAMCACCGCATAGCTTTGATATTMATGTCGGAMGACTAMTATATAGCATCGCTA

3511 MATAGGACMATTTAAGMAGGATCTGTTCACTGTTTCMATMAGGCTGACATGGCAMTACTAGTGACCMACATCCAMTGMAGATA $N K$ K D N L R K D L F T V S I K A D M A M T S D

3601 AATTTGGACGMAGTTGMAGA CTTATACTTCCCGATGMATGCTTCAGTACTTAAACTTGGTAAMGACGACACMATCATTTGGAMAM

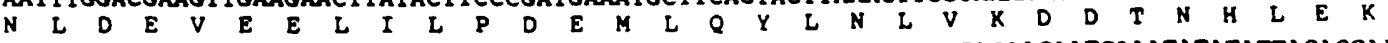

3691 GAACATCAAGCTGTACCTGTGGGGTCAAATGTATCCGAAACTATAGCTTCAAACCACTACCGAGAACAATCAMATATATATTACACCAAT

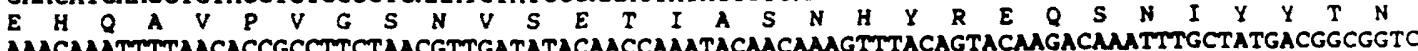

3781 MACMATTTTAACACCGCCTTCTAACGTTGATATACAACCAMATACAACAAAGTTTACAGTACAAGACAMATTTGCTATGACGGCGG GGGGGTTCATTCAGTCAMAGAGMTTMAGTACCCTAGCTGTACCAMTGMACATGGGCATGCCAMATGCGAAGCTTCCATCACCAGTCT G G S S F S S Q R 3961 CAMANTATATGMCACTGACATTGGCTCCAAGCAGCAATCAGCATTACCGTCAGCTCATCAACGGCNACAGMAMATCMATTATAAT Q $K$ K M N T D I G S K Q Q S A

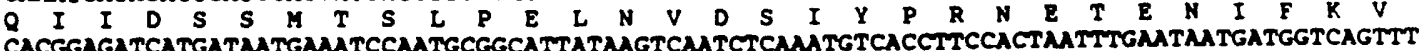
1141 CACGgAGATCATGATATGAMTCCMATGCGGCATTATAGTCAMTCTCAMTGTCACCTTCCACTAATTTGMATATGATGGTCAGTT

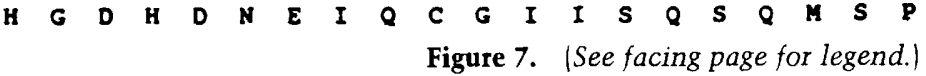




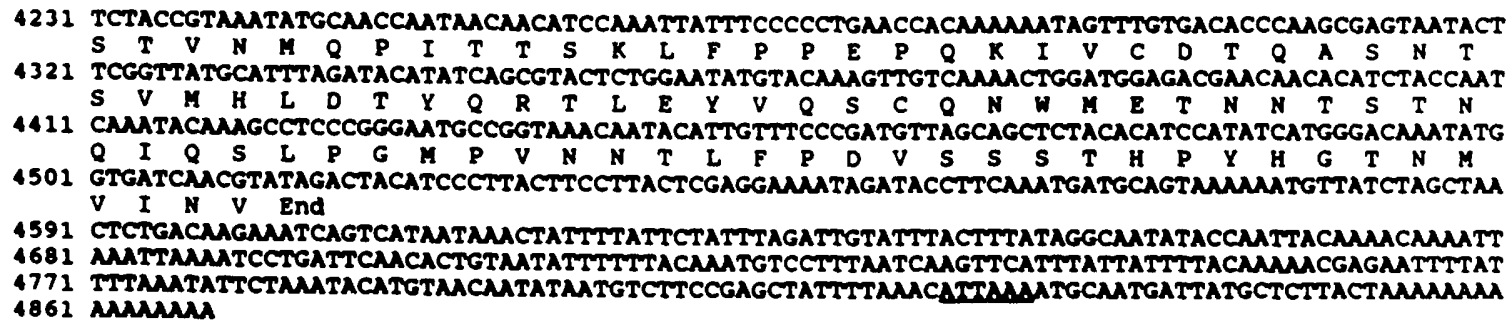

Figure 7. Nucleotide and predicted amino acid sequence of the three partial cDNA clones $9-11,8-5$, and 8 , which span the coding region of the $\mathrm{ci}^{D}$ transcript. The zinc-finger region of the amino acid sequence is shown in bold. cDNA 8 , which was used for most of the expression pattern analysis, begins at nucleotide 3732 .

tively. A third hypothesis is that the complementation observed is due to transvection. Evidence suggests that the $\mathrm{ci}^{D}$ mutation is a promoter mutation-one that essentially eliminates the major transcript of the $c i^{D}$ locus. The expression pattern of the $c i^{D}$ transcript in homozygous $\mathrm{Ce}$ embryos appears to be normal, suggesting that the $c i^{D}$ promoter functions normally in $\mathrm{Ce}$ mutants. It is possible that wild-type promoter sequences on the $C e$ chromosome can direct the synthesis of a wild-type transcript from the $\mathrm{Ci}^{D}$ chromosome in transheterozy. gotes. Similar transvection effects have been seen in the Bithorax complex and in the decapentaplegic locus (Lewis 1954; Gelbart 1982a,b). To examine whether either of the second two possibilities is correct, we are attempting to isolate probes specific to the second transcript, and we are going to examine the consequence of chromosome pairing on the phenotype of $c i^{D} / C e$ heterozygotes.

\section{$\mathrm{ci}^{\mathrm{D}}$ encodes a DNA-binding protein}

The $c i^{D}$ transcript encodes a series of tandem repeats with similarity to the zinc-finger domains of TFIIIA and $\mathrm{Kr}$ (Brown et al. 1985; Miller et al. 1985; Rosenberg et al. 1986). TFIIIA has been shown to bind both DNA and RNA, and, although it is an RNA polymerase III transcription factor, the zinc-finger domain has been found in proteins that are putative RNA polymerase II transcription factors. Recently, the three-dimensional structure of a zinc-finger repeat that closely represents the consensus sequence, has been determined by NMR (Lee et al. 1989). The determined structure is very similar to the structure proposed by Berg (1988) in which a zinc atom is bound by two conserved Cys and His residues and the remainder of the polypeptide is folded into a helix packed against two $\beta$ strands. Basic and polar amino acid residues on the exposed surface of the helix may be involved in DNA binding.

Of particular interest is the similarity between $c i^{D}$ and the human GLI protein (Kinzler et al. 1988). GLI has been implicated in neoplastic growth because of its amplification in several human glioblastomas. A number of Drosophila developmental genes have been found to encode proteins with similarity to growth factors and oncogenes. These include the segment polarity gene $w g$, which is the homolog of int-1 (Rijsewijk et al. 1987); the decapentaplegic $(d p p)$, which belongs to the TGF- $\beta$ family (Padgett et al. 1987); the maternal gene dorsal that is similar to c-rel (Steward 1987); torso, which encodes a tyrosine kinase (Sprenger et al. 1989); polehole, which is the homolog of v-raf (Ambrosio et al. 1989) and the neurogenic genes Notch and Delta that encode proteins with EGF-like repeats (Wharton 1985; Vassin 1987). These similarities suggest that genes whose expression or function is altered in transformed tissue may have normal functions in development.

The similarity of the $c i^{D}$ repeats to known transcription factors provides strong evidence that one function of $c i^{D}$ is to regulate transcription of other genes. Recently, it has been demonstrated that GLI is located predominantly in the nucleus and that it binds DNA in a sequence-specific manner (Kinzler and Vogelstein 1990). Several binding sites in the human genome were identified. The high degree of similarity between $c i^{D}$ and $G L I$ in the putative DNA-binding region may suggest that they bind to very similar nucleotide sequences. It has been shown that the target specificity of the glucocorticoid receptor can be converted to that of the estrogen receptor by changing 3 amino acids in the first zinc finger or to that of the thyroid hormone receptor by replacing 5 amino acids in the second zinc finger (Umesono and Evans 1989). Likely targets of $c i^{D}$ transcriptional regulation are other members of the segment polarity class and genes involved in specifying cell fate.

\section{Spatial pattern of expression}

The pattern of $c i^{D}$ expression during development is curious. It is expressed uniformly throughout the blastoderm stage and gastrulation and does not resolve into segmentally repeating stripes until the end of the short phase of germ-band extension. A similar pattern of expression is seen with the segment polarity gene ptc through this stage. The other zygotic segment polarity genes that have been cloned are expressed initially in stripes by late cellular blastoderm or early gastrulation. The initial uniform expression of $c i^{D}$ and the relatively late development of periodic expression indicate that the generation of the striped expression pattern is the result of negative regulation of $c i^{D}$ transcripts within the posterior quarter of the segment. The negative regulation is, in all likelihood, mediated by one of the other segment polarity genes because many of these genes are expressed throughout germ-band elongation. This appears 
to be the case: Eaton and Kornberg (1990) report that in en mutants, $c i^{D}$ transcripts fail to resolve into stripes. Similarly, ptc expression, which is coincident with the $c i^{D}$ expression pattern at the end of the short phase of germ-band elongation, also fails to resolve into stripes in en mutants (Hooper and Scott 1989).

The expression of the $c i^{D}$ transcript in the anterior three-quarters of the segment during germ-band elongation was a surprising result because this expression pattern is not consistent with the mutant phenotype of homozygous $c i^{D}$ embryos (Fig. 6). The $c i^{D}$ mutation causes the posterior half of each segment to be eliminated and replaced with a mirror image duplication of the anterior half of the segment. Thus, $c i^{D}$ is expressed in the anterior half of the segment, which does not appear to require $c i^{D}$ function, and it is not expressed in the posterior quarter of the segment, a region which is altered in the mutant. There are at least two interpretations of this result. The first is that $c i^{D}$ function is nonautonomous and that the cells that express $c i^{D}$ are communicating information to cells in the posterior quarter of the seg. ment that is essential to their appropriate development. Sequence data imply that $c i^{D}$ binds DNA and regulates transcription of other genes. This argues against it being directly involved in cell-cell communication, but it is possible that the $c i^{D}$ product may regulate the expres-

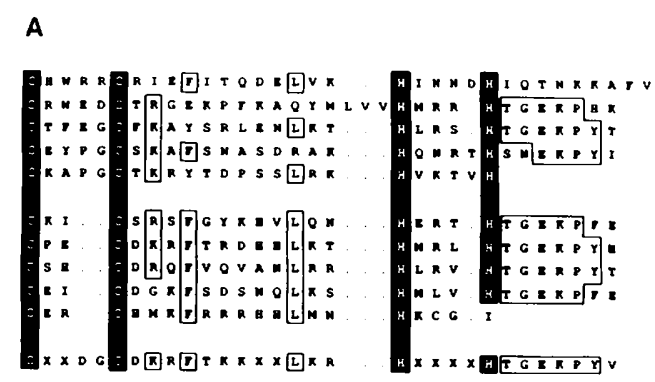

\section{B}

KVNSRLDEY INCGS IS I PSNEY DCANADTTDI KDEPGDF IETNCHWRRCRI IEF ITQDELV

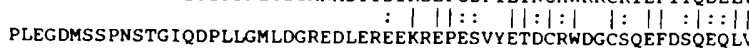
KH INNDH IQTNKKAFVCRWEDCTRGEKPF KAQYMLVVHMRRHTGEKPHKCTFEGCFKAYS

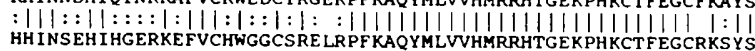
RLENLKTHLRSHTGEKPYTCEY PGCS KAFSNASDRAKHQNRTHSNEKPYICKAPGCTKRY

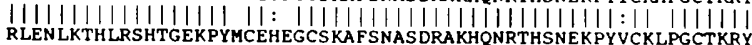
TOPSS LRKHVKTVHGAEFYANKKHKGLPLNDANSRLQQNNSRHNLQEHNI DSSPCSEDSH ||||||||||||||$|:::::|:|:| \quad::::|=\quad::: \quad:|: \quad:::|:|: \mid:$ TDPSS LRKHVKTVHG PDAHVTKRHRG---DGPLPRAPS ISTVEPKRER--EGGPIREESR LGKMLGTSSPS I KSESDISSSNHHLVNGVRA---SDSLLTY SPDDLAENL-NLDDGWNCD

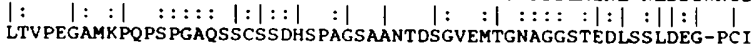
DDVDVADLPI VLRAMVNIGNGNASASTIGGSVLARQRFRGRLQTKG I NSST IMLCN I PES

$:::::: 1$
AGTGLSTLRRENLRLDQLHQLRPIGTRGLKLPSLSHTGTTVSRRVGPPVSLERRSSSS

Figure 8. (A) Sequence comparison of $c i^{D}$ finger repeats to the $\mathrm{Kr}$ and TFIIIA finger domains. A consensus sequence is shown for TFIIIA. X represents any amino acid, and ellipses were used to align sequences. $(B)$ Sequence comparison of $\mathrm{Ci}^{D}$ zinc-finger domain and some flanking sequences to the zinc-finger domain and flanking sequences of the human GLI protein. A vertical line marks identical residues and a colon shows conservative substitutions. sion of other genes that are involved in this process. The predicted protein products of the ptc and wg genes indicate that these genes probably function directly in cellcell communication, and $c i^{D}$ may regulate their expression.

A second interpretation is that the requirement of $c i^{D}$ function for proper development of posterior structures occurs before germ-band extension. At this time, the $c i^{D}$ transcript is uniformly expressed and could specifically function in posterior cells. Even though $c i^{D}$ is expressed in anterior cells, it may function only in posterior cells in conjunction with posterior-specific gene products such as the $g s b$ gene, which also encodes a transcription factor. The repression of $c i^{D}$ expression in the posterior quarter of the segment may be related to its later function in the anterior compartment of imaginal discs. We can choose between these two possible roles for the $\mathrm{ci}^{D}$ gene by examining the autonomy of the $c i^{D}$ mutant phenotype. However, the lack of suitable larval cuticle markers on the fourth chromosome has precluded us from performing a mosaic analysis to test for autonomy. We hope to use our cosmid containing a large region of genomic sequences around the $c i^{D}$ transcript to move the $c i^{D}$ gene to another chromosome with appropriate markers. This will allow us to test for autonomy of $\mathrm{ci}^{D}$ and to distinguish between these two interpretations.

\section{Materials and methods}

Stocks

The Celey ${ }^{D}$ stock was obtained from B. Hochman (University of Tennessee); $M^{63 a} / c^{D}$ and the Oregon-R came from the Mid America Stock Center (Bowling Green, Ohio), and the P stock came from $G$. Rubin.

\section{Cuticle preparations}

Embryos were mounted in a $1: 1$ mixture of Hoyer's solution and lactic acid (Van der Meer 1977; G. Struhl, pers. comm.) and photographed under phase contrast.

\section{P-element mutagenesis}

A $\mathrm{P} ; \mathrm{ci}^{D} / e y^{D}$ line was generated by crossing $c i^{D} / \mathrm{M}^{63 a}$ males to $\mathrm{P}$ females and $C e / e y^{D}$ males to $P$ females. The $c i^{D /}+$ and $e y^{D} /+$ males were collected and backcrossed to $P$ females. After several backcrosses, the $c i^{D /}+$ and the $e y^{D /}+$ progeny were crossed to each other to generate the $\mathrm{P} ; \mathrm{ci}^{D} / \mathrm{ey}^{D}$ stock.

$\mathrm{P}_{;} c i^{D} / e y^{D}$ males were crossed to $\mathrm{y}_{;} c i^{D} / e y^{D}$ females. The dysgenic progeny of this cross were collected and crossed and mated among themselves. Thirty-five individual lines of dysgenic progeny were set up for mating. The adult progeny of these second matings were screened for reversion of the dominant wing vein defect (interruption of L4 and L5 distal to anterior cross veins) to wild type. The majority of apparent revertants isolated turned out to be recombinants of the genotype $+/ e y^{D}$. Normally, there is no recombination on the fourth chromosome, but under dysgenic conditions recombination can occur. Recombination $\left(+/ e y^{D}\right)$ and insertion $\left(c^{D R P} / e y^{D}\right)$ events were distinguished by crossing all apparent revertants to $c i^{D /}$ 
$e y^{D}$ flies. Three P-element insertion lines $\left(c i^{D R P 21.2}, c i^{D R P 24.2}\right.$, and $c i^{\text {DRP26.6 }}$ were identified in this manner.

\section{Cloning}

Genomic DNA was prepared according to Roberts (1986). Libraries were constructed by partial $\mathrm{Mbol}$ digestion of genomic DNA, size selection of DNA from 15 to $20 \mathrm{~kb}$ on sucrose step gradients, and ligation into BamHI-digested EMBL4 (Frischauf et al. 1984). The cosmid library and a 0 - to 24-hr cDNA library were the kind gift of John Tamkun. A 0- to 16-hr cDNA library was the kind gift of Bernd Hovemann. Nick-translated DNA probes were used for screening libraries (Rigby et al. 1977). Standard protocols were used in the screening for genomic and cDNA clones (Maniatis et al. 1982). Scanning densitometry was performed using an LKB densitometer.

\section{Northern analysis}

RNA was isolated from embryos at various stages of development, and from larvae, pupae, and adults according to McKenzie et al. (1975) and Henikoff and Meselson (1977). RNA samples were fractionated in formaldehyde agarose gel and transferred to Nylon membranes (Schleicher \& Schuell) (Maniatis et al. 1982). ${ }^{32} \mathrm{P}$-labeled nick-translated probes were used to probe blots. Hybridizations and wash conditions were as in Maniatis et al. (1982).

\section{In situ hybridizations to embryos}

Embryos were embedded in wax. Sections 18 and $6 \mu \mathrm{m}$ in length) were probed with single-stranded ${ }^{35}$ S-labeled RNA probes generated from cDNAs subcloned in pGEM-4Z or pGEM-7Z (Melton et al. 1984; Promega). Hybridization and washing conditions were as in Ingham et al. (1985). Wholemount in situ hybridizations were performed according to Tautz and Pfeifle (1989) as modified by Oh and Edgar (pers. comm.).

\section{Sequence analysis}

Sequence analysis was performed according to Sanger et al. (1977). Nested deletions were made using the procedure of Henikoff (1987) and most of the sequence was determined on both strands. The search of the EMBL/GenBank Data Library was performed using the TFastA program (Lipman and Pearson 1985) from the Genetics Computer Group sequence analysis software package.

\section{Acknowledgments}

We thank John Tamkun and Joan Hooper for providing us with the cosmid library; Bernd Hoveman for providing us with a 0 to 24-hr cDNA library; Nick Baker for providing us with a wg probe; Thomas Kornberg and Suzanne Eaton for open discussions, for sharing information on the expression of $c i^{D}$ in imaginal discs, and for advice on the Genius protocol; Doug Engel and members of his laboratory for their generosity in sharing their expertise, equipment, and reagents; Rick Gaber for his help in preparing Figure 8A; Kelly Mayo and Teresa Woodruff for advice on the in situ hybridization protocol, and the other members of our laboratory for helpful discussions and encouragement. This work was supported by a Basil O'Connor starter scholar research award 5-572 from the March of Dimes birth defects foundation and National Science Foundation grant DCB 89-01394.

\section{Note added in proof}

Sequence data described in this paper have been submitted to the EMBL/GenBank Data Libraries.

\section{References}

Akam, M. 1987. The molecular basis for metameric pattern in the Drosophila embryo. Development 101: 1-22.

Ambrosio, L., A.P Mahowald, and N. Perrimon. 1989. Requirement of the Drosophila raf homologue for torso function. Nature 342: 288-291.

Anderson, K.V. and J.A. Lengyel. 1981. Changing rates of DNA and RNA synthesis in Drosophila embryos. Dev. Biol. 82: $127-138$.

Baker, N. 1987. Molecular cloning of sequences from wingless, a segment polarity gene in Drosophila: The spatial distribution of a transcript in embryos. EMBO J. 6: 1765-1773.

- 1988. Embryonic and imaginal requirements for wingless, a segment polarity gene in Drosophila. Dev. Biol. 125: 96-108.

Baumgartner, S., D. Bopp, M. Burri, and M. Noll. 1987. Structure of two genes at the gooseberry locus related to the paired gene and their spatial expression during Drosophila embryogenesis. Genes Dev. 1: 1247-1267.

Berg, J. 1986. Potential metal-binding domains in nucleic acid binding proteins. Science 232: 485-487.

- 1988. Proposed structure for the zinc-binding domains from transcription factor IIIA and related proteins. Proc. Natl. Acad. Sci. 85: 99-102.

Bingham, P.M., M.G. Kidwell, and G.M. Rubin. 1982. The molecular basis of P-M hybrid dysgenesis: the role of the P-element, a P-strain-specific transposon family. Cell 29: $995-$ 1004.

Blumberg, H., A. Eisen, A. Sledziewski, D. Bader, and E.T. Young. 1987. The zinc fingers of a yeast regulatory protein shown by genetic evidence to be essential for its function. Nature 328: 443-445.

Bopp, D., M. Burri, S. Baumgartner, G. Frigerio, and M. Noll. 1986. Conservation of a large protein domain in the seg. mentation gene paired and in functionally related genes of Drosophila. Cell 47: 1033-1040.

Boulay, J.L., C. Dennefeld, and A. Alberga. 1987. The Drosophila developmental gene snail encodes a protein with nucleic acid binding fingers. Nature 320: 395-398.

Brown, R.S., C. Sander, and P. Argos. 1985. The primary structure of transcription factor TFIIIA has 12 consecutive repeats. FEBS Lett. 186: 271-274.

Campos-Ortega, J. and V. Hartenstein. 1985. The embryonic development of Drosophila melanogaster. Springer-Verlag, Berlin.

Cavener, D. 1987. Comparison of the consensus sequence flanking the translational start sites in Drosophila and vertebrates. Nucleic Acids Res. 15: 1353-1361.

Cote, S., A. Preiss, J. Haller, R. Schuh, A. Kielin, E. Seifert, and H. Jackle. 1987. The gooseberry-zipper region of Drosophila: Five genes encode different spatially restricted transcripts in the embryo. EMBO I. 6: 2793-2802.

DesPlan, C., J. Theis, and P. O'Farrell. 1985. The Drosophila developmental gene, engrailed, encodes a sequence-specific DNA binding activity. Nature 318: 630-635.

DiNardo, S., E. Sher, J. Heemskerk-Jongens, J. Kassis, and P. H. $\mathrm{O}^{\prime}$ Farrell. 1988. Two-tiered regulation of spatially patterned engrailed gene expression during Drosophila embryogenesis. Nature 332: 604-609.

Eaton, S. and T. Kornberg. 1990. Repression of cubitus inter- 
ruptus Dominant expression in the posterior compartment by engrailed. Genes Dev. 4: 1074-1083.

Fjose, A., W.J. McGinnis, and W.J. Gehring. 1985. Isolation of a homeo box-containing gene from the engrailed region of Drosophila and the spatial distribution of its transcripts. Nature 313: 284-289.

Frischauf, A., H. Lehrach, A. Poustka, and N. Murray. 1983. Lambda replacement vectors carrying polylinker sequences. J. Mol. Biol. 170: 827-842.

Gelbart, W.M. 1982a. Synapsis dependent allelic complementation at the decapentaplegic complex in Drosophila melanogaster. Proc. Nat1. Acad. Sci. 79: 2636-2640.

- $1982 \mathrm{~b}$. Interactions of zeste mutations with loci exhibiting transvection effects in Drosophila melanogaster. Genetics 102: 179- 189 .

Grau, Y. and P. Simpson. 1987. The segment polarity gene costal-2 in Drosophila. I. The organization of both primary and secondary embryonic fields may be affected. Dev. Biol. 122: $186-200$.

Hanas, J.S., D.J. Hazuda, D.F. Bogenhagen, F.Y.-H. Wu, and C.-W. Wu. 1983. Xenopus transcription factor A requires zinc for binding to the 5S RNA gene. I. Biol. Chem. 258: $14120-14125$.

Hartshorne, T.A., H. Blumberg, and E.T. Young. 1986. Sequence homology of the yeast regulatory protein ADRl with Xenopus transcription factor TFIIIA. Nature 320: 283-287.

Henikoff, S. 1987. Unidirectional digestion with Exonuclease III in DNA sequence analysis. Methods Enzymol. 155: 156165.

Henikoff, S. and M. Meselson. 1977. Transcription of two heat shock loci in Drosophila. Cell 12: 441-451.

Hochman, B. 1971. Analysis of chromosome 4 in Drosophila melanogaster. II. Ethyl methanesulfonate induced lethals. Genetics 67: 235-252.

- 1973. Analysis of a whole chromosome in Drosophila. Cold Spring Harbor Symp. Quant. Biol. 38: 581-589.

- 1976. The fourth chromosome of Drosophila melanogaster. In The genetics and biology of Drosophila (ed. M. Ashburner and E. Novitski|, pp. 903-928. Academic Press, New York.

Hooper, J.E. and M.P. Scott. 1989. The Drosophila patched gene encodes a putative membrane protein required for segmental patterning. Cell 59: 751-765.

Ingham, P.W. 1988. The molecular genetics of embryonic pattern formation in Drosophila. Nature 335: 25-33.

Ingham, P.W., K.R. Howard, and D. Ish-Horowicz. 1985. Transcription pattern of the Drosophila segmentation gene hairy. Nature 318: 439-445.

Jurgens, G., E. Wieschaus, C. Nüsslein-Volhard, and H. Kluding. 1984. Mutations affecting the pattern of the larval cuticle in Drosophila melanogaster. II. zygotic loci on the third chromosome. Wilhelm Roux's Arch. Dev. Biol. 193: $283-295$.

Kadonaga J.T., K.R. Carner, F.R. Masiarz, and R. Tjian. 1987. Isolation of cDNA encoding transcription factor $\mathrm{Spl}$ and functional analysis of the DNA binding domain. Cell 51: $1079-1090$.

Kinzler, K.W. and B. Vogelstein. 1990. The GLI gene encodes a nuclear protein which binds specific sequences in the human genome. Mol. Cell. Biol. 10: 634-642.

Kinzler, K.W., S.H. Bigner, D.D. Bigner, J.M. Trent, M.L. Law, S.J. O'Brien, A.J. Wong, and B. Vogelstein. 1987. Identification of an amplified, highly expressed gene in a human glioma. Science 236: 70-73.

Kinzler, K.W., J.M. Ruppert, S.H. Bigner, and B. Vogelstein. 1988. The GLI gene is a member of the Kruppel family of zinc finger proteins. Nature 332: 371-374.

Kornberg, T. 1981 a. engrailed: A gene controlling compartment and segment formation in Drosophila. Proc. Natl. Acad. Sci. 78: 1095-1098.

- $1981 \mathrm{~b}$. Compartments in the abdomen of Drosophila and the role of the engrailed locus. Dev. Biol. 86: 363-381.

Kornberg, T., I. Siden, P. O'Farrell, and M. Simon. 1985. The engrailed locus of Drosophila: In situ localization of transcripts reveals compartment-specific expression. Cell 40: $45-63$.

Kuner, J.M., M. Nakanishi, Z. Ali, B. Drees, E. Gustavson, J. Theis, L. Kauvar, T. Kornberg, and P. O'Farrell. 1985. Molecular cloning of engrailed: A gene involved in the development of pattern in Drosophila melanogaster. Cell 42: 309316.

Lawrence, P.A. and G. Morata. 1976. Compartments in the wing of Drosophila: A study of the engrailed gene. Dev. Biol. 50: 321-337.

Lawrence, P.A. and G. Struhl. 1982. Further studies of the engrailed phenotype in Drosophila. EMBO /. 1: 827-833.

Lee, M.S., G.P. Gippert, K.V. Soman, D.A. Case, and P.E. Wright. 1989. Three-dimensional solution structure of a single zinc finger DNA-binding domain. Science 245: 635637.

Lewis, E.B. 1954. The theory and application of a new method of detecting chromosomal rearrangements in Drosophila melanogaster. Amer. Nat. 88: 225-239.

Lindsley, D.L. and E.H. Grell. 1968. Genetic variations of Drosophila melanogaster. Carnegie Inst. Wash. Publ. No. 627.

Lipman, D.J. and W.R. Pearson. 1985. Rapid and sensitive protein similarity searches. Science 243: 1681-1688.

Maniatis, T., E. Fritsch, and J. Sambrook. 1982. Molecular cloning: A laboratory manual. Cold Spring Harbor Laboratory Press, Cold Spring Harbor, New York

Mariol, M.C., T. Preat, and B. Limbourg-Bouchon. 1987. Molecular cloning of fused, a gene required for normal segmentation in the Drosophila melanogaster embryo. Mol. Cell. Biol. 7: 3244-3251.

Martinez-Arias, A., N. Baker, and P. Ingham. 1988. Role of segment polarity genes in the definition and maintenance of cell states in the Drosophila embryo. Development 103: $157-170$.

McKenzie, S.L., S. Henikoff, and M. Meselson. 1975. Localization of RNA from heat-induced polysomes at puff sites in Drosophila melanogaster. Proc. Natl. Acad. Sci. 72: 11171121.

Melton, D., P. Krieg, M. Rebagliat, T. Maniatis, K. Zinn, and M.R. Green. 1984. Efficient in vitro synthesis of biologically active RNA and RNA hybridization probes from plasmids containing a bacteriophage SP6 promoter. Nucleic Acids Res. 12: 7035-7056.

Miller, J., A.D. McLachlan, and A. Klug. 1985. Repetitive zincbinding domains in the protein transcription factor IIIA from Xenopus oocytes. EMBO /. 4: 1609-1614.

Modolell, J., W. Bender, and M. Meselson. 1983. Drosophila melanogaster mutations suppressible by the suppressor of Hairy-wing are insertions of a 7.3-kilobase mobile element. Proc. Nat1. Acad. Sci. 80: 1678-1682.

Moses, K., M.C. Ellis, and G.M. Rubin. 1989. The glass gene encodes a zinc-finger protein required by Drosophila photoreceptor cells. Nature 340: 531-536.

Nakano, Y., I. Guerrero, A. Hildago, A. Taylor, J. Whittle, and P. Ingham. 1989. A protein with several possible membranespanning domains encoded by the Drosophila segment polarity gene patched. Nature 341: 508-513.

Nüsslein-Volhard, C. and E. Wieschaus. 1980. Mutations af- 
fecting segment number and polarity in Drosophila. Nature 287: 795-801.

Nüsslein-Volhard, C., E. Wieschaus, and H. Kluding. 1984. Mutations affecting the pattern of the larval cuticle in Drosophila melanogaster. I. Zygotic loci on the second chromosome. Wilhelm Roux's Arch. Dev. Biol. 193: 267-282.

Orenic, T., J. Chidsey, and R. Holmgren. 1987. Cell and cubitus interruptus Dominant: Two segment polarity genes on the fourth chromosome in Drosophila. Dev. Biol. 124: 50-56.

Padgett, R.W., R.D. St. Johnston, and W.M. Gelbart. 1987. A transcript from a Drosophila pattern gene predicts a protein homologous to the transforming growth-factor family. $\mathrm{Na}$ ture 325: 81-84.

Perrimon, N. and A.P. Mahowald. 1987. Multiple functions of segment polarity genes in Drosophila. Dev. Biol. 119: 587600.

Perrimon, N., L. Engstrom, and A.P. Mahowald. 1989. Zygotic lethals with specific maternal effect phenotypes in Drosophila melanogaster. I. Loci on the X chromosome. Genetics 121: 333-352.

Poole, S. and T. Kornberg. 1988. Modifying expression of the engrailed gene of Drosophila melanogaster. Development (suppl.) 104: 85-93.

Poole, S., L. Kauvner, B. Drees, and T. Kornberg. 1985. The engrailed locus of Drosophila: Structural analysis of an embryonic transcript. Cell 40: 37-43.

Rigby, P.W.J., M. Dieckmann, C. Rhodes, and P. Berg. 1977. Labelling deoxyribonucleic acid to high specific activity in vitro by nick translation with DNA polymerase I. I. Mol. Biol. 113: 237.

Riggleman, B., E. Wieschaus, and P. Schedl. 1989. Molecular analysis of the armadillo locus: Uniformly distributed transcripts and a protein with novel internal repeats are associated with a Drosophila segment polarity gene. Genes Dev. 3: $96-113$.

Rijsewijk, F., M. Schuermann, E. Wagenaar, P. Parren, D. Weigel, and R. Nusse. 1987. The Drosophila homolog of the mouse mammary oncogene int-1 is identical to the segment polarity gene wingless. Cell 50: 649-657.

Roberts, D.B. (ed.) 1986. Drosophila, a practical approach. IRL Press, Oxford.

Rosenberg, U.B., C. Schroder, A. Preiss, A. Kienlin, S. Cote, I. Riede, and H. Jackle. 1986. Structural homology of the product of the Drosophila Kruppel gene with Xenopus transcription factor IIIA. Nature 319: 336-339.

Rubin, G. and A. Spradling. 1982. Genetic transformation of Drosophila with transposable element vectors. Science 218: $348-353$.

Sanger, F., S. Nicklen, and A.R. Coulson. 1977. DNA sequencing with chain-terminating inhibitors. Proc. Natl. Acad. Sci. 74: 5463-5467.

Scott, M.P. and S.B. Carroll. 1987. The segmentation and homeotic gene network in early Drosophila development. Cell 51: 689-698.

Smith, D.R., I.J. Jackson, and D.D. Brown. 1984. Domains of the positive transcription factor specific for the Xenopus $5 \mathrm{~S}$ RNA gene. Cell 37: 645-652.

Sprenger, F., L.M. Stevens, and C. Nüsslein-Volhard. 1989. The Drosophila gene torso encodes a putative receptor tyrosine kinase. Nature 338: 478-479.

Steward, R. 1987. Dorsal, and embryonic polarity gene in Drosophila, is homologous to the vertebrate proto-oncogene, c-rel. Science 238: 692-694.

Tautz, D. and C. Pfeifle. 1989. A non-radioactive in situ hybridization method for the localization of specific RNAs in Drosophila embryos reveals translational control of the seg- mentation gene hunchback. Chromosoma 98: 81-85.

Tautz, D., R. Lehmann, H. Schnurch, R. Schuh, E. Seifert, A. Kienlin, K. Jones, and H. Jackle. 1987. Finger protein of novel structure encoded by hunchback, a second member of the gap class of Drosophila segmentation genes. Nature 327: 383-389.

Umesono, K. and R.M. Evans. 1989. Determinants of target gene specificity for steroid/thyroid hormone receptors. Cell 57: 1139-1146.

van den Heuvel, M., R. Nusse, P. Johnston, and P. Lawrence. 1989. Distribution of the wingless gene product in Drosophila embryos; a protein involved in cell-cell communication. Cell 59: 739-749.

Van der Meer, J. 1977. Optically clean and permanent whole mount preparations for phase contrast microscopy of cuticular structures of insect larvae. Drosophila Inf. Serv. 52: 160.

Vassin, H., K.A. Bremer, E. Knust, and J.A. Campos-Ortega 1987. The neurogenic gene Delta of Drosophila melanogaster is expressed in neurogenic territories and encodes a putative transmembrane protein with EGF-like repeats. EMBO I. 11: 3431-3440.

Vincent, A., H.V. Colot, and M. Rosbash. 1985. Sequence and structure of the Serendipity locus of Drosophila melanogaster. A densely transcribed region including a blastodermspecific gene. J. Mol. Biol. 186: 149-166.

Wharton, K.A., K.M. Johansen, T. Xu, and S. Artavanis-Tsakonas. 1985. Nucleotide sequence form the neurogenic locus Notch implies a gene product that shares homology with proteins containing EGF-like repeats. Cell 43: 567581 .

Wieschaus, E., C. Nüsslein-Volhard, and G. Jurgens. 1984. Mutations affecting the pattern of the larval cuticle in Drosophila melanogaster. III. Zygotic loci on the X-chromosome and fourth chromosome. Wilhelm Roux's Arch. Dev. Biol. 193: $296-307$ 


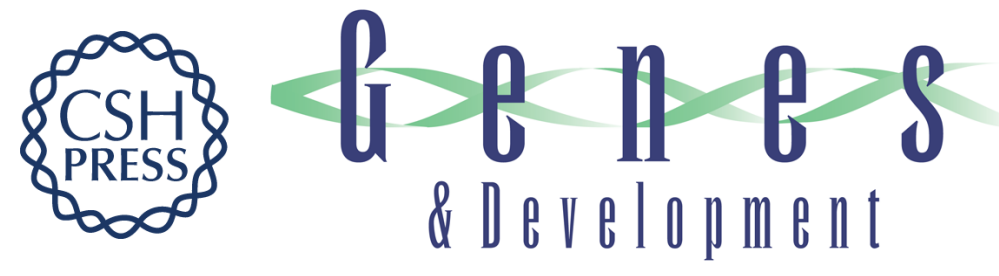

\section{Cloning and characterization of the segment polarity gene cubitus interruptus Dominant of Drosophila.}

T V Orenic, D C Slusarski, K L Kroll, et al.

Genes Dev. 1990, 4:

Access the most recent version at doi:10.1101/gad.4.6.1053

References This article cites 81 articles, 20 of which can be accessed free at: http://genesdev.cshlp.org/content/4/6/1053.full.html\#ref-list-1

License

Email Alerting

Service

Receive free email alerts when new articles cite this article - sign up in the box at the top right corner of the article or click here.

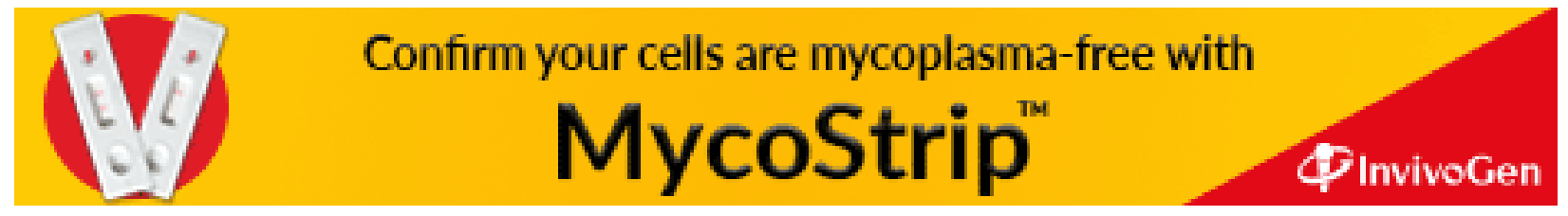

